\title{
Biogeographic patterns of the East African coastal forest vertebrate fauna
}

\author{
Ermias T. Azeria · Isabel Sanmartín · Stefan Ås · \\ Allan Carlson $\cdot$ Neil Burgess
}

Received: 17 June 2005/ Accepted: 27 February 2006

(C) Springer Science+Business Media B.V. 2007

\begin{abstract}
The archipelago-like coastal forest of East Africa is one of the highest priority ecosystems for biodiversity conservation worldwide. Here we investigate patterns of species richness and biogeographic distribution among birds, mammals and reptiles of these forests, using distribution data obtained from recently published reviews and information collated by the WWF Eastern Africa Coastal Forest Ecoregion Programme. Birds and mammals species were divided into forest specialists and generalists, and forest specialist reptiles into 'coastal' and 'forest' endemics. The species richness of birds and generalist mammals increased with area, and is probably a result of area-dependent extinction. Only in birds, however, species richness increased with decreasing isolation, suggesting possible isolation-dependent colonization. Forest diversity, associated to altitudinal range, is important for specialist birds and mammals, whose species richness increased with wider altitudinal range. The number of relict coastal endemic and forest endemic reptiles was higher in forests with wider altitudinal ranges and on relatively higher altitude, respectively. Such forests have probably provided a suitable (and perhaps stable) environment for these species through time, thus increasing their persistence. Parsimony
\end{abstract}

E. T. Azeria · A. Carlson

Department of Conservation Biology, Swedish University of Agricultural Sciences, 7002, SE-750 07

Uppsala, Sweden

I. Sanmartín · S. Ås

Evolutionary Biology Centre, Uppsala University, Norbyvägen. 18D, SE-752 36 Uppsala, Sweden

A. Carlson

WWF-Sweden, Ulriksdals Slott, SE-170 81 Solna, Sweden

N. Burgess

WWF-USA Conservation Science Programme, 1250 24th St NW, Washington, DC, USA

N. Burgess

Conservation Biology Group, Zoology Department, Cambridge University, CB2 3EJ Cambridge, UK

E. T. Azeria $(\bowtie)$

Department of Biology, McMaster University, 1280 Main St. West, Hamilton, ON L8S 4K1, Canada e-mail: Ermias.Azeria@nvb.slu.se 
analysis of distributions (PAD) and cluster analyses showed geographical distance and general ecological similarity among forests as a determinant factor in bird distribution patterns, with compositional similarity decreasing with increasing inter-forest distance. Compositional similarity patterns of mammals among the forests did not show a strong geographical correspondence or a significant correlation with inter-forest distance, and those of reptiles were not resolved, with very low similarity levels among forest faunas. Our results suggest that the relative importance (and causal relationship) of forest attributes affecting the distribution of the East African coastal forest vertebrate fauna varies depending on life history traits such as dispersal ability and forest specialization. The groupings in PAD are partly congruent with some of the previous classifications of areas of endemism for this region, supporting the 'naturalness' of these regions.

Keywords Biogeography - Conservation - East Africa coastal forests · Fragmentation · Species-area relationship - Isolation - Altitude $\cdot$ Parsimony analysis of distributions · Relict fauna

\section{Introduction}

Fragmentation of once continuous habitats entails habitat loss, degradation and increased isolation, and ultimately the loss of biodiversity (Andrén 1994; Cornelius et al. 2000; Brooks et al. 2002). Ecologically important processes during fragmentation are similar to those influencing biotas of 'true' islands (MacArthur and Wilson 1967). The species richness in the remnant fragments, according to MacArthur and Wilson (1967), is primarily the result of a dynamic balance between two opposing processes, area-dependent extinction and isolation-dependent colonization. Species richness is therefore expected to increase with increasing area and/or decreasing isolation from the species source pool (MacArthur and Wilson 1967; Rosenzweig 1995; Whittaker 1998).

However, fragments may also differ in ecological factors other than area and isolation (e.g. Diamond 1981; Stuart 1981), as well as community dynamics in such fragments may depart from colonization-extinction equilibrium (Whittaker 1998; Lomolino 2000). For example, forest fragments may span smaller or larger altitudinal ranges, and forests incorporating a greater altitudinal range are expected to cover a larger span of habitats and hence harbour more species (e.g. Kingdon and Howell 1993; Ås et al. 1997). Similarly, ecological factors that determine species number are also determinants in species composition (e.g. Whittaker 1998; Lomolino 2000). For example, species composition of communities is expected to be more similar among geographically closer fragments than among more distant ones because of more habitats in common and higher rate of 'interfragment' dispersal (Power 1975; Nekola and White 1999; Ricklefs and Lovette 1999; Morand 2000; Azeria 2004).

However, the relative importance of these factors in determining species distribution throughout the fragmented habitat differs among taxa, depending on life history traits such as dispersal ability (birds vs. reptiles) and level of dependence on the forest resources (specialists vs. generalists) (Ricklefs and Lovette 1999; Gascon et al. 1999; Watson 2002). Moreover, historical factors (e.g. past distribution and fragmentation), origin of the biota (e.g. relict species vs. species derived from the surrounding matrix), and species geographical ranges have a profound effect on species distribution patterns (e.g. Ricklefs 
and Schluter 1993; Welter-Schultes and Williams 1999; Jetz and Rahbek 2002; Watson 2002; Jetz et al. 2004).

The coastal forests of Eastern Africa form an archipelago of forests extending along the coastal plain of East Africa from southern Somalia to northern Mozambique. Located within the so-called "Swahili regional centre of endemism and Swahili-Maputaland regional transition zone" (Clarke 2000), they form one of the major centres of endemism in Africa (Burgess and Clarke 2000; Brooks et al. 2001). The large number of endemic species, high biodiversity, and concentration of rare and threatened taxa make the coastal forests of East Africa one of the highest priority ecosystems for conservation in Africa and globally (Hawthorne 1993; Burgess and Clarke 2000; Myers et al. 2000; Brooks et al. 2001, 2002; Burgess et al., 2004). Despite their biological importance, however, the unique fauna and flora of these forests are currently threatened by human disturbance, through increasing fragmentation and forest degradation (e.g. Hawthorne 1993; Brooks et al. 2002).

The current view is that their present archipelagic distribution is the remnant of a once continuous forest that extended over tropical Africa in the Early Tertiary. This later became fragmented by the gradual desiccation of the continent that started in the Miocene and, more recently, by increasing human habitat destruction (Moreau 1933; deMonocal 1995; Clarke 2000b; Clarke and Karoma 2000 and references therein). Most coastal forest endemics have a narrow distributional range, often exhibiting single-site endemism or disjunct distributional patterns (Burgess et al. 1998). They do not seem to be part of a recent local radiation, but show closer relationships to West African lineages, or represent 'ancient lineages' that have gone extinct elsewhere (Burgess et al. 1998; Burgess 2000). Rodgers (2000) suggests that the ancient forest was probably heterogeneous, with patchy ecological conditions, even before the onset of fragmentation. Therefore, the variation in distribution patterns between forest fragments that we observe today is probably the result of both recent ecological and historical factors.

The last decade has witnessed an increase in the number of biogeographic studies on the coastal forest biota (Burgess et al. 1998; Burgess and Clarke 2000, and references therein). Most of these studies have focused on studying distributional patterns of endemic species, by simply plotting numbers of coastal forest endemics onto a map, which are then used to define 'centres of endemism' for conservation policies (Burgess et al. 1998; Burgess and Clarke 2000; but see de Klerk et al. 2002b). However, more analytical approaches are now available that can be used to visualize biotic relationships among areas. Cluster analysis based on similarity indices has been the traditional method to group areas based on their compositional similarity. An expansion of parsimony analysis of endemicity (PAE, Rosen 1988) that takes into account an ecological interpretation, parsimony analysis of distributions (PAD, Trejo-Torres and Ackerman 2001), has recently arisen as an alternative to phenetic multivariate methods in biogeographic analysis. Like cluster analysis, PAD uses presence/absence matrices to construct branching diagrams of area relationships, and can be used as a method to find hierarchical structure in biogeographical data, i.e., nested sets of area relationships (Trejo-Torres and Ackerman 2001; Cavieres et al. 2002; GarcíaBarros et al. 2002).

In this study, we will use PAD to analyse biogeographical affinities among the coastal forests using recent data on species distributions of birds, mammals, and reptiles, and compare those groupings with current definitions of 'centres of endemism' (Burgess et al. 1998; Burgess 2000). Moreover, we will use cluster analysis to group areas based on their compositional similarity, and test whether this similarity can be explained by 'inter-forest dispersal'. Finally, we will analyse the effects of ecological attributes of the forest, such as 
forest size, isolation, median altitude, and elevation range, in the variation of species richness between forest fragments. Because different taxa may respond differently to ecological attributes, we adopt here a comparative approach and investigate species richness and compositional similarity patterns among forests across three vertebrate groups: birds vs. mammals vs. reptiles. We also examine differences in species richness between habitat generalists and forest specialists. This approach will give us an insight into the effect of life history characteristics on current species patterns, and help us to understand differences in forests affinities between taxonomic groups, which could then be used for conservation strategies.

\section{Materials and methods}

The study system

The East African coastal forests (Fig. 1) are a set of tiny forests found on the coastal belt of East Africa, and often imbedded within a much larger habitat mosaic of farmland, savannah-woodland, and thickets. The forests themselves cover a total area of 3,172 sq. $\mathrm{km}$, consisting of over 260 forest patches varying in size and degree of isolation; most of them are less than 500 ha in size (Burgess and Clarke 2000). The forest belt extends from southern Somalia south to Mozambique (i.e. between $1^{\circ} \mathrm{N}$ to $25^{\circ} \mathrm{S}$ and $34^{\circ}-$ $41^{\circ} \mathrm{E}$ ), distributed over six countries: Somalia, Kenya, Tanzania, Mozambique, Zimbabwe, and Malawi. The limits to the coastal forest area are set by rainfall (decreasing to the north), seasonality (increasing to the south), and by altitude, increasing to the west, where they can extend from sea-level to a maximum altitude of $1,100 \mathrm{~m}$, depending on local ecological conditions. Coastal forests also may be found in areas with a low mean annual rainfall $(<470 \mathrm{~mm}$ ), growing along river banks (Burgess et al. 1998; Clarke 2000a, b).

The word 'coastal forest' in itself is a broad term used to define a mosaic of forest types including the typical semi-evergreen and evergreen dry forest, variant type and sub-type (scrub forest, Brachystegia forest) and transitional vegetation formations (e.g. riverine, swamp, Afromontane transition forests) (for a definition, see Hawthorne 1993; Rodgers 2000; Clarke 2000a, and references therein).

\section{Data treatment}

Presence-absence matrices of species by forests were obtained from three recent reviews of the East African coastal forest fauna: birds (Mlingwa et al. 2000), mammals (Burgess et al. 2000), and reptiles (Broadley and Howell 2000). The three reviews are based on published and unpublished data collected during several research programs that have been active in the coastal forests of East Africa during the last decade (see the data sources for detailed references). These sources were updated in 2004 using information collected for the WWF Eastern Africa Coastal Forest Ecoregion Programme (WWF-EARPO 2002; Anonymous 2003; Burgess et al. 2004; WWF unpublished). Although survey effort has not been fully standardized between sites, the time spent in each forest was considerable (tens to hundreds of man days) and thus we consider that the species lists available are adequate to detect broad biogeographical groupings between forests. Data on birds and mammals are the most comprehensive, particularly for birds, which can be sampled in mist nets and 


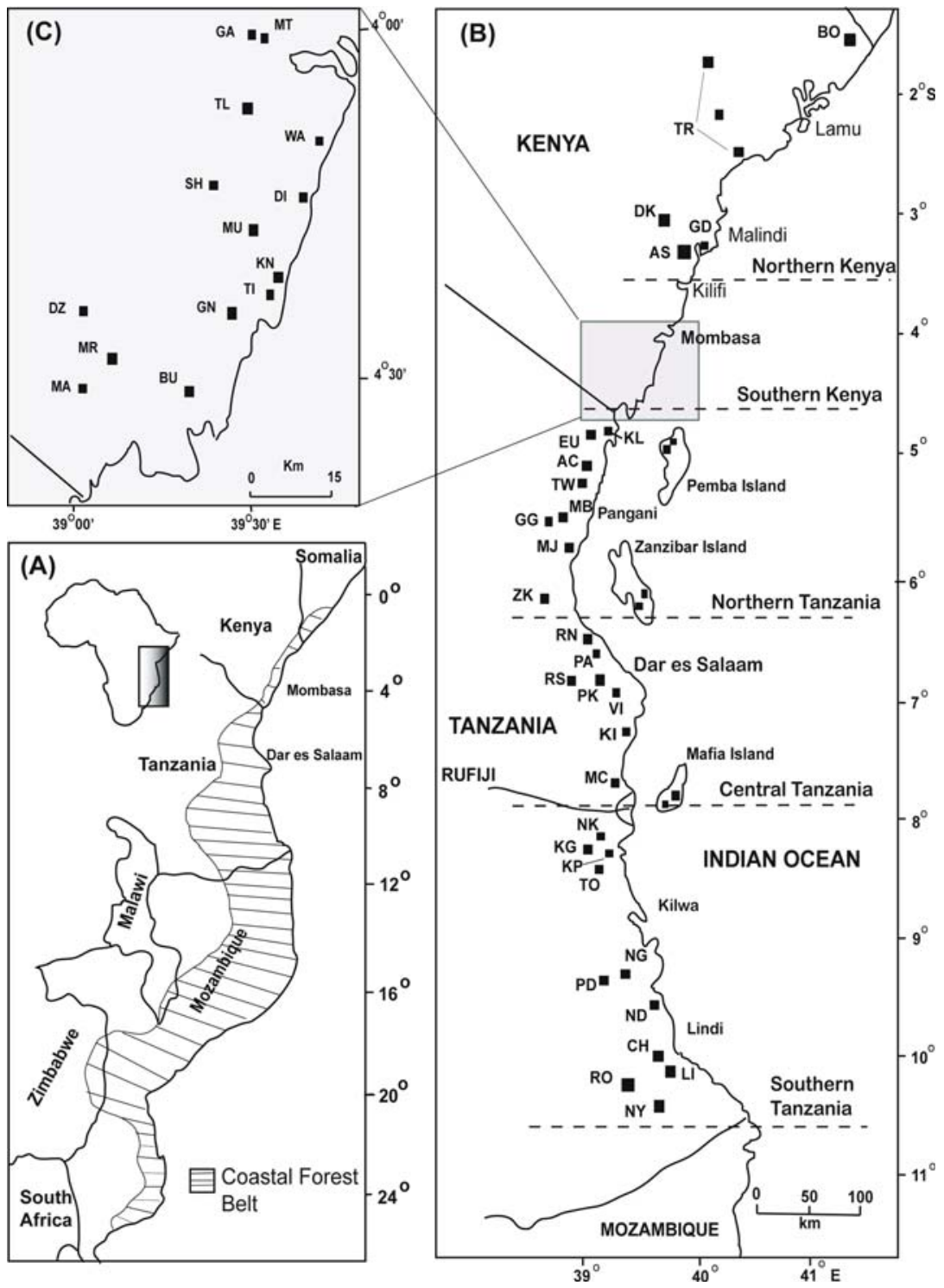

Fig. 1 Map of study area showing (A) the general location of the East African coastal forests; (B) Location of the coastal forest fragments included in this study; (C) Details of southern Kenya indicating the location of the coastal forest fragments studied in this region. Adapted from Burgess et al. (1998). Abbreviations (north to south): $\mathrm{BO}=\mathrm{Boni} ; \mathrm{TR}=$ Tana river primate and delta; $\mathrm{DK}=$ Dakatcha; $\mathrm{GD}=\mathrm{Gede}$; AS = Arabuko Sokoke; GA = Gandini $; \quad$ MT = Mtswakara $; \quad \mathrm{TL}=$ Teleza $; \quad$ WA = Waa $; \quad$ DI $=$ Diani; $\mathrm{SH}=$ Shimba Hills; $\mathrm{MU}=$ Muhaka $\quad \mathrm{KN}=$ Kinondo, $\mathrm{TI}=$ Timbwa; $\mathrm{GN}=$ Gongoni $\quad \mathrm{DZ}=\mathrm{Dzombo}$; $\mathrm{MR}=$ Mrima; $\mathrm{MA}=$ Marenji $\mathrm{BU}=\mathrm{Buda} ; \mathrm{EU}=$ Eastern Usambara lowland $; \mathrm{KL}=\mathrm{Kilulu} ; \mathrm{AC}=\mathrm{Amboni}$ Caves $; \mathrm{TW}=$ Tongwe $; \mathrm{MB}=$ Msumbugwe $; \mathrm{GG}=$ Gendagenda $; \mathrm{MJ}=$ Mkwaja; $\mathrm{ZK}=$ Zaraninge-Kiono; $\mathrm{RN}=$ Ruvu North; PA = Pande; RS = Ruvu South; PK = Pugu and Kazimzumbwi; VI = Vikindu; $\mathrm{KI}=$ Kisiju; $\mathrm{MC}=$ Mchungu; $\mathrm{NK}=$ Namakutwa; $\mathrm{KG}=$ Kiwengoma; KP = Kitope; TO = Tong'omba; NG = Ngarama; PD = Pindiro; ND = Ndimba CH = Chitoa RO = Rondo $;$ LI = Litipo; NY = Nyangamara. Other localities not shown in the map but included in the study are Jubba River (southern Somalia), Kimboza (Tanzania), and forests in the offshore islands of Pemba Island (PI), Zanzibar Island (ZI), and Mafia Island (MI) 
observed directly and recorded through calls. For mammals the lack of bat netting at some sites means that all bat assemblage data were excluded from analysis, but as trapping was undertaken at all sites, rodents and shrews have been included. The lists of reptile species per forest are likely to be the least complete, due to the lack of a standard sampling protocol and difficulty of observation and trapping. Further reptile sampling would likely increase the number of 'coastal endemic' reptile species, in particular those of the dense forest and forest edge, many of which are fossorial herpetofauna (Broadley and Howell 2000). Hence the biogeographical zonation obtained for reptiles is likely to be the least robust to the addition to new data.

Within each faunal group, we distinguished two different categories based on the level of dependence on forest resources, and according to the classifications used in the original studies:

(a) 'Forest specialists' are species strictly dependent on the forest interior, so they are likely to disappear if the forest is modified.

(b) 'Forest generalists' are species that depend upon undisturbed forests for some of their resources, for example nesting sites in birds, but which are also able to live at the edge of the forest or in modified, managed, or secondary forests.

The original reptile study (Broadley and Howell 2000) considered two different categories: 'coastal endemics' - species which are endemic to the coastal forests, and 'forest endemics'-species that are also found in the nearby Eastern Arc Mountain forests. We have grouped these two categories under specialists in our study. No generalist species were considered in Broadley and Howell's (2000) analysis but non-forest species made up for a great part of the total reptile diversity.

Species-richness pattern

In all, a total of 163 species and 53 forests found in Somalia, Kenya and Tanzania (Table 1) were included in our study (Fig. 1). Data on area size (minimum forest area), and median and range of altitude for each forest fragment were obtained from Burgess and Clarke (2000). When a habitat is patchily distributed in the landscape, measuring the degree of isolation is not straightforward. In our analysis, we have adopted an approach commonly used in metapopulation studies. Thus, the 'isolation index' for each forest was computed after Hanski and Thomas (1994), as follows:

$$
I i=1 / \max 10 \Sigma A j \exp ^{-\alpha D i j},
$$

where $A j$ (in $\mathrm{km}^{2}$ ) is the area of the neighbouring forest, $D i j$ is the distance (in $\mathrm{km}$ ) from the study or focal forest $i$ to the neighbouring forest $j$ (including forests not included in our study), and $\alpha$ (alpha) is the effect of distance on isolation. The first ten larger values of the expression $A j \exp ^{-\alpha D i j}$ were taken. Three different alpha values were tried $(0.1,0.2$, and $0.5)$, arranged by decreasing weight given to long distances. Birds did show a significant correlation between species richness and isolation for all three values of alpha, but no significant correlation was found for either mammals or reptiles. An alpha value of 0.2 was chosen for birds and reptiles because it also gave the best fit for the normality assumption of residuals. For mammals, an alpha value of 0.5 showed the best fit. Inter-forest distance was estimated from the coordinates (centre) of each forest. Larger values of the isolation index " $I i$ " indicate higher isolation of the forest. 
Table 1 Number of vertebrate species and number of forest fragments (with at least one confirmed species presence) of the East African coastal forest included in this study, according to taxa and specialization level

Taxonomic groups Specialization groups No. of forests No. of species Species richness (Mean \pm SD)

\begin{tabular}{llllc}
\hline Birds & Specialists & 43 & 35 & $11.49 \pm 6.28$ \\
& Generalists & 43 & 48 & $23.44 \pm 7.46$ \\
\multirow{3}{*}{ Mammals } & Total & 43 & 83 & $34.93 \pm 13.11$ \\
& Specialists & 30 & 23 & $4.07 \pm 1.98$ \\
& Generalists & 30 & 43 & $10.17 \pm 6.07$ \\
Reptiles & Total & 30 & 66 & $14.23 \pm 7.41$ \\
& Specialists & $22(3)$ & 37 & $3.52 \pm 2.68$ \\
& Coastal endemic & $18(7)$ & 23 & $1.88 \pm 1.88$ \\
& Forest endemic & $19(6)$ & 14 & $1.58 \pm 1.60$ \\
\hline
\end{tabular}

Number of species does not include other species that are present in coastal forests but absent in forests included in this study (see Tables 5-7 for a complete list). Species richness (mean \pm standard deviation) is shown. Numbers in brackets are forests with no recorded species

The correlation between each of the variables - area, altitude, and isolation - and the species richness of the three vertebrate group across forests was studied first by using simple correlation and regression analyses, and finally by multiple regression analysis (MINITAB v. 13.31). We initially examined three simple regression/correlation functions: untransformed (linear), semi-log and $\log -\log$. Log-transformation of area and isolation better approximated the normality distribution of values and had also a slightly better fit than the other functions. In a few cases, however, the linear model showed a better fit (see Results). Median altitude and altitudinal range were fitted to a linear function, but partial correlations were used because the two variables were significantly correlated to each other ( $r=0.73-0.95, P<0.001$ for all three groups).

\section{Biogeographical affinities}

\section{Cluster analysis}

Cluster analysis is a method for grouping areas according to their overall biotic similarity (Van Tongeren 1995). Similarity distances between areas are calculated based on a wide array of similarity indices (e.g., Jaccard, Sorensen), and dendrograms are produced from the resulting similarity matrices. We use two similarity indices in our analysis. The 'Sorensen's similarity index' is calculated as $\operatorname{Sor}=2 C /(A+B)$, where $C$ is the number of species common to both areas, and $A$ and $B$ are the total number of species occurring in each of the areas (Krebs 1999). This index takes the total species number of the two areas (the denominator) into account, so similarity values strongly depend on the difference in species richness between the two areas. The second index, the 'Simpson's coefficient of similarity', is not sensitive to differences in species numbers (Patterson and Brown 1991), but gives more weight to the number of shared species. Simpson's similarity index is computed as: Simp=C/N small, where $N_{\text {small }}$ is the number of species in the area with the lowest species number. An UPGMA dendrogram was constructed based on the Sorensen's similarity matrices. Additionally, a Mantel test of correlation between matrices was used to find whether compositional similarity (number of shared species) between each pair of forest fragments was correlated to the geographic distance between fragments. The significance of the correlation was tested against random values from 1,000 simulations, using the program PC-ORD (McCune and Mefford 1997). Inter-forest distance ranged from $1.80 \mathrm{~km}$ (Mtswakara to Gandini) to $1,300 \mathrm{~km}$ (Jubba to Rondo). 
PAD (Trejo-Torres and Ackerman 2001, also called PASA in Trejo-Torres and Ackerman 2002) is an ecological extension of the parsimony analysis of endemicity, PAE (Rosen 1988). PAE is a method to group areas based on their shared taxa according to the most parsimonious solution (criterion of simplicity or 'parsimony') (Rosen 1988; Morrone 1994). Taxa that are restricted to two or more of the studied areas are considered in PAE as analogous to shared derived characters (synapomorphies) in phylogenetic analysis, indicating a unique biotic history among the areas analysed (but see Brooks and Van Veller 2003). PAD is identical to PAE in execution but the interpretation of the results is more ecological. PAD cladograms are considered as hypotheses of biotic similarities between areas, and the terminal dichotomies in PAD are interpreted as areas that share the maximum biogeographic affinity (Trejo-Torres and Ackerman 2001; García-Barros et al. 2002).

A data matrix of forest by species was constructed for each group of taxa (see Table 1 for number of forests and species included in the analysis; Appendices 5-6 for the complete data matrices). A hypothetical, 'primitive' area coded 'all zeros' was incorporated to the matrix as an outgroup to root the trees. This ensures that the biogeographic relationships depicted in the PAD cladogram are mainly based on the appearance (gain) of new species (1) by the area, instead of on taxa losses (0). The same reasoning is used in cluster analysis to favour similarity indices that give more value to presence than absence data (Trejo-Torres and Ackerman 2002).

In PAD, single-area endemics and cosmopolitan species (species that are present in all areas) do not provide information about area relationships and are usually removed from the analysis (Trejo-Torres and Ackerman 2001; García-Barros et al. 2002); this is analogous to removing autapomorphies from a phylogenetic analysis. However, an area that does not share species with other areas but contains many single-area endemics can still be interesting from a conservation viewpoint. Therefore, we decided to include all the original species in our PAD analysis. This also makes the results from PAD comparable with those derived from the cluster analysis, which is based on complete biotas. All species usually receive the same weight in $\mathrm{PAD}$, irrespective of their distributional ranges. However, species belonging to different guilds (e.g., specialists vs. generalists) should be differently treated (e.g. Trejo-Torres and Ackerman 2001). In our analysis, forest specialist species were given a weight of 2 to emphasize their dependence to the forest ecosystem, and therefore their importance as biotic markers. We compared these results with those of an unweighted analysis to analyse the effects of weighting in PAD. In all cases, the trees from the weighted analyses were longer but considerably better resolved than those from the unweighted analysis (not shown). For the cluster analysis, there was no difference between the weighted and unweighted matrices, so only the unweighted results are given.

The data matrix was analysed under the maximum parsimony criterion using the heuristic search in PAUP 4.0b10 (Swofford 2002). When more than one most parsimonious tree (MPT) was found, both strict and Adams consensus trees were computed to reflect the common groupings. The strict consensus tree reflects only those groupings that are present in all MPT trees. The Adams consensus is particularly useful in recovering common structure when incongruence is mainly caused by a few unstable taxa (Page 1998); for example forests that occupy very different positions among the trees.

For comparative purposes, each taxonomic group (birds, mammals, and reptiles) was analysed separately. However, an alternative approach was tried in which we combined all datasets in one single analysis. The objective was to examine patterns of biogeographical 
affinity defined by the correlation between all three groups. Because the original studies did not include the same set of areas (only 16 forests were common to the three studies), we compared only forests for which we have data for at least two of the groups studied: 29 forests in all. This means that several forests lack data for part of the taxa, but this is not necessarily an impediment for a simultaneous analysis: a direct relationship between missing data and ambiguity of results has yet to be proved (Kearney 2002). However, conclusions from this analysis should be taken with caution.

\section{Results and discussion}

Ecological determinants of species richness

Species richness of birds, both specialist and generalist, was higher in larger and less isolated forests (Table 2, see also Mlingwa et al. 2000). Moreover, the number of both specialists and generalists also increased with increasing altitudinal range (Table 2). Similarly, when forests area, isolation and altitudinal range were entered into multiple regression models, all had a significant explanatory effect for the species richness of the specialists (Multiple $r^{2}=0.66, F=25.93$, d.f. $\left.=(3,39), P<0.0001\right)$, whereas altitude range was only marginally significant $(P=0.064)$ for species richness of the generalist birds (Multiple $r^{2}=0.55, F=15.96$, d.f. $\left.=(3,39), P<0.0001\right)$.

Species richness of generalist mammals was positively correlated to forest area, whereas the number of specialist mammals increased with increasing altitudinal range (Table 2). Similarly, in the multiple regression analyses only area had a significant $(P<0.01)$ effect on species richness of generalist mammals (Multiple $r^{2}=0.393, F=15.96$, d.f. $=(4,25)$, $P<0.05)$. For forest specialist mammals, only the multiple regression model with median and altitude range was marginally significant (Multiple $r^{2}=0.162, F=2.6$, d.f. $=(2,27)$, $P<0.10)$, and only altitude range had a significant effect $(P<0.05)$ in the model.

Species richness of forest specialist reptiles was higher in forests with higher median altitude and wider altitude range if univariate correlations were considered (median: $r=0.55, P<0.01$; range: $r=0.56, P<0.01$ ), but no significant correlations were found after partialling out (controlling) the effect of the two altitude components (Table 2). When

Table 2 Relationship between species richness of vertebrates in the East African coastal forests in relation to area, isolation, and altitude

\begin{tabular}{|c|c|c|c|c|c|}
\hline \multirow[t]{2}{*}{ Taxa } & \multirow[t]{2}{*}{ Groups } & \multirow[t]{2}{*}{$\log ($ Area $)\left(r^{2}\right)$} & \multirow[t]{2}{*}{$\log$ (Isolation) $(r)$} & \multicolumn{2}{|l|}{ Altitude } \\
\hline & & & & Range $\left(r_{\mathrm{p}}\right)$ & $\operatorname{Median}\left(r_{\mathrm{p}}\right)$ \\
\hline \multirow[t]{2}{*}{ Birds } & Specialists & $0.33 * * *$ & $-\mathbf{0 . 3 9} * *$ & $0.51 * * *$ & 0.09 \\
\hline & Generalists & $0.33 * * *$ & $-0.34 * * *$ & $0.44 * *$ & -0.02 \\
\hline \multirow[t]{2}{*}{ Mammals } & Specialists & 0.09 & $-0.29^{\mathrm{u}}$ & $0.37 *$ & -0.25 \\
\hline & Generalists & $0.30 * *$ & $-0.26^{\mathrm{u}}$ & 0.23 & -0.13 \\
\hline \multirow[t]{3}{*}{ Reptiles } & Specialists & 0.08 & $-0.19^{\mathrm{u}}$ & 0.214 & -0.07 \\
\hline & Coastal endemic & $0.124^{\mathrm{a}, \mathrm{u}}$ & $-0.15^{\mathrm{u}}$ & $0.52 * *$ & $-0.39^{\mathrm{a}}$ \\
\hline & Forest endemic & 0.02 & -0.17 & -0.30 & $0.43^{*}$ \\
\hline
\end{tabular}

$r=$ Pearson correlation coefficient, $r^{2}=$ simple linear regression coefficient. For median and range of altitude, partial correlations $\left(r_{\mathrm{p}}\right)$ were calculated because the two variables were highly correlated to each other. Significant correlations are shown in bold. 'U': linear form of the predictor was used for the analyses $* * * P<0.001 ; * * P<0.01 ; * P<0.05 ;{ }^{\mathrm{a}} P<0.10$ 
the two groups of specialist reptiles ('forest' and 'coastal' endemics) were considered separately, they showed significant correlations to different components of altitude. Species richness of coastal endemic reptiles tended to increase with increasing altitudinal range, whereas that of forest endemics showed a positive correlation to the median altitude (Table 2). Moreover, coastal endemic reptiles showed a marginally significant correlation to the median altitude (of negative sign) and to area size. A similar relationship was obtained in the multivariate regression analysis. Only altitude range was significantly $(P<0.05)$ correlated to species richness of coastal endemics (Multiple $r^{2}=0.433, F=3.82$, d.f. $=(4,20), P<0.05)$, whereas median altitude was the only significantly $(P<0.05)$ correlated variable to species richness of 'forest endemics' (Multiple $r^{2}=0.374, F=2.98$, d.f. $=(4,20), P<0.05)$. None of the mammal or reptile groups displayed a significant relationship to measure of isolation between forest fragments (Table 2).

The species-area relationship found here for birds and generalist mammals is consistent with the predictions of the Island Biogeography Theory (MacArthur and Wilson 1967; Rosenzweig 1995), and it is probably an effect of area-dependent extinction. It also corroborates earlier findings for various East African forest ecosystems (Diamond 1981; Stuart 1981; Newmark 2002). The general lack or the existence of a weak species-area relationship in reptiles could be due to several reasons, such as the long-term isolation and cycles of environmental fluctuation of the system, anthropogenic disturbances that could have led to a non-equilibrium condition (e.g., Whittaker 1998), or could simply being the result of a sampling artefact or undersampling of this group.

The fact that only birds showed a significant negative relationship between species richness and isolation is probably related to their higher dispersal ability. Mobile organisms like birds are expected to be able to disperse across gaps of unsuitable habitat and are therefore more likely to benefit from the 'rescue effect' (Brown and Kodric-Brown 1977), and from decolonization processes. On the other hand, isolation may not be an explanatory factor of species richness variability in groups of organisms with weak dispersal ability (Lomolino et al. 1989). In our study, this applies to forest specialist mammals and to endemic reptiles, in particular (see also Table 3), which are known for their poor ability to disperse (e.g., Foufoupolos and Ives 1999; Morand 2000). Thus, the extinction-colonization equilibrium (MacArthur and Wilson 1967) may not apply for these groups.

Altitude is an important determinant of species richness in terrestrial communities. A coastal forest spanning over a wide altitudinal range probably has a more diverse environment than one with a narrower range (Kingdon and Howell 1993; Jetz and Rahbek 2002). For example, altitudinal range was found to be one of the core predictors of species richness for range-restricted sub-Saharan birds (Jetz and Rahbek 2002). As expected in habitat specialists (e.g. Ricklefs and Lovette 1999), habitat diversity (i.e. altitude range) influenced the species richness of forest specialist birds and mammals, and also that of coastal endemic reptiles. The pattern shown by the relict coastal endemic reptiles may also reflect historical refugee opportunities, i.e. a more stable environment provided by the altitudinal range (topographic heterogeneity). Concentrations of range-restricted relict endemics on some localities may reflect low rates of extinction due to high environmental stability (e.g. Fjeldså and Lovett 1997; Fjeldså et al. 1997; de Klerk et al. 2002a). However, a correspondence between centres of endemism and altitudinal range measured at a larger scale (one degree latitude $\times$ one degree longitude) for sub-Saharan bird fauna was interpreted as topographic heterogeneity reflecting "historical opportunities for allopatric speciation" (Jetz et al. 2004). Such historical interpretation of the relationship between altitude range and number of endemics, in this case as reflecting opportunity for speciation 
Table 3 Similarity in species composition between East African coastal forests in relation to geographical distance between forests

\begin{tabular}{llcc}
\hline & & Sorensen & Simpson \\
\hline \multirow{2}{*}{ Birds } & Specialists & $\mathbf{- 0 . 2 5 * *}$ & $\mathbf{- 0 . 2 2 5 * *}$ \\
& Generalists & $-\mathbf{0 . 1 8 *}$ & $\mathbf{- 0 . 2 9} * * *$ \\
Mammals & Specialists & 0.059 & 0.008 \\
& Generalists & 0.061 & -0.015 \\
Reptiles & Specialists & -0.044 & -0.043 \\
& Coastal endemics & -0.12 & -0.14 \\
& Forest endemics & 0.006 & -0.023 \\
\hline
\end{tabular}

A Mantel test based on Sorensen's and Simpson's similarity indexes was used to test the significance of the correlation. Significant correlations are shown in bold

$* * * P<0.001 ; * * P<0.01 ; * P<0.05$

or as a refugee, may be further resolved by including information on the phylogenetic relationships among the endemic species.

Interestingly, species richness of forest endemic reptiles was higher in forests with a high median altitude. This is probably because forest endemics include mountain species that are mainly restricted to higher altitude forests (e.g. Tongwe, Tong'omba, and Rondo). Coastal forests with higher median altitude are expected to be better developed, i.e., moist forests with tall trees because they receive more rainfall (e.g. Hawthorne 1993; Lowe and Clarke 2000), and are probably less subjected to human disturbance (Clarke 2000b) than low lying forests. This may also have a historical explanation in that high altitude forests are ancient forests that may have survived during cycles of arid climate and coastal inundations, and possibly acted as refugia harbouring species that went extinct in low-lying forests during those periods (see also Burgess et al. 1998).

\section{Biogeographical affinities among the East African coastal forest faunas}

A parsimony analysis of bird distributions based on 43 coastal forest fragments resulted in two most parsimonious trees (MPTs, $\mathrm{L}=588, \mathrm{CI}=0.20, \mathrm{RI}=0.57$ ), whose strict consensus is shown in Fig. 2A. The Adams consensus was identical to the strict consensus. Forest characterizations given below are based on descriptions from Mlingwa et al. (2000).

The most distal clade of the cladogram (A) includes large or well-studied forests in northern Kenya (e.g., Arabuko-Sokoke). These forests are the sister-group to a second clade (B) formed by the sacred 'Kaya' forests in southern Kenya (e.g., Diani), which are protected under tribal laws. The sister-group to these Kenyan forests $(A+B)$ is a clade (c), comprising the Pugu Hills and the East Usambara lowland forests in northern Tanzania, and its sister-clade (D), composed of forests in southern Tanzania corresponding to the 'Lindi' local centre of endemism and nearby forests (e.g., Litipo, Ngarama) (Burgess 2000), as well as four other forests in northern Tanzania (e.g., Gendagenda). The forest in the first three clades (A-C) belong to the so-called 'Usambara-Kwale' local centre of endemism and to other 'minor' centres of endemism (e.g., Arabuko-Sokoke) recognized in previous studies (Burgess et al. 1998; Burgess 2000, Appendix Table 4). Diverging basally to the whole distal clade (Tana to Msubugwe) are forests that correspond geographically to central Tanzania (e.g., Pande, Vikindu; Fig. 1).

The distal part of the cladogram explained above indicates that compositional similarity of bird assemblages between forest fragments is spatially autocorrelated, i.e. geographically close forests have similar bird faunas. The cluster tree in Fig. $2 \mathrm{~B}$ also shows a 
A.

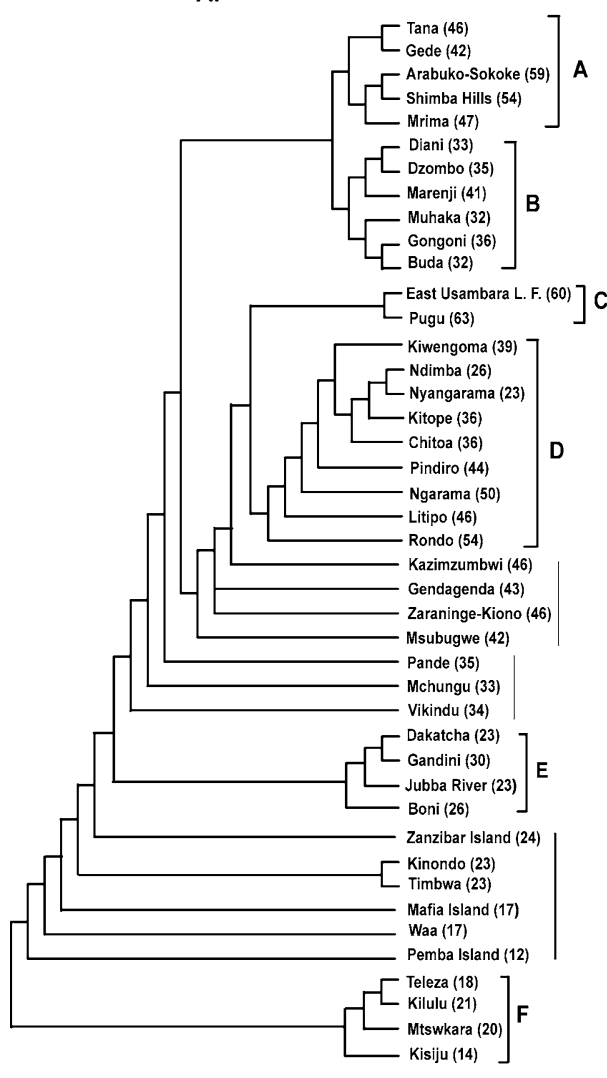

B.

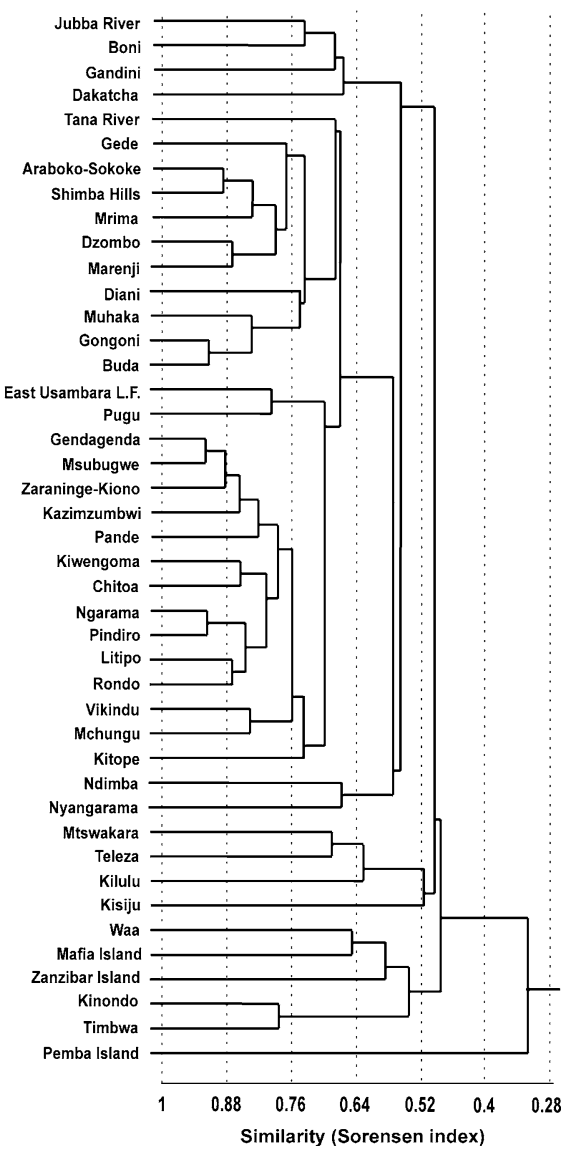

Fig. 2 Biogeographic affinities among 43 East African coastal forests based on the distributions of specialist and generalist birds. (A) Strict consensus of two MPTs $(\mathrm{L}=588, \mathrm{CI}=0.20, \mathrm{RI}=0.57)$ obtained from a parsimony analysis of species distributions; number of species in each forest fragment is given between brackets. (B) UPGMA tree from a cluster analysis based on Sorensen's similarity index

similar pattern, with many of the higher-level clusters grouping forests that are geographically close. Moreover, these clusters are joined by high Sorensen's similarity values (SS = 0.7-0.8), indicating a high degree of similarity among their forest bird faunas (Fig. 2B). This is further corroborated by the Mantel test (Table 3), which shows a general decrease of compositional similarity with increasing geographic distance (see also the negative correlation between isolation and species richness in Table 2). These results suggest that geographical distance is one of the main factors determining biogeographical affinities among bird communities (see also Stuart 1981; Morand 2000; Azeria 2004).

However, this geographic pattern can also be explained by other ecological factors such as forest habitat type, since forests of similar type are usually found closer to each other. For example, bird faunas of the well developed but fairly small forests in clade B showed closer affinity to other, large forests within the main forest block (A) than to similar sized and geographically close scrubby forests (e.g., Waa, Timbwa). Similarly, other studies in coastal forests of south Kenya have found forest structure to be more important than area as 
determinant of the composition of understory bird fauna (Mlingwa et al. 2000). Thus, type and structure of the forests influence the species richness and composition of bird communities. However, finer details of forest structure type, such as tree height or cover of forest canopy, may not always be spatially autocorrelated, depending on local aspects such as topography and associated soil structure, or anthropogenic effects (e.g., Lowe and Clarke 2000).

The remaining groups at the base of the tree do not follow so clearly a geographical pattern but are better explained by similarities in vegetation and other ecological factors. For example, clade (E) is composed of a tight group of forests in the northern limit of the coastal forest belt, in southern Somalia and northern Kenya, consisting of relatively dry and low forests (e.g., Jubba) or small and dense woodland forests (e.g., Gandini). Diverging basal to this clade are several depauperated forests, either because of their island condition (e.g., Pemba) or because they correspond to very small, scrubby forest fragments $(<0.5$ sq. $\mathrm{km})$ such as Waa. The last clade $(\mathrm{F})$ is formed by a group of geographically scattered but ecologically similar forests (e.g., Teleza), which are described as scrubby forests associated with low rainfall and/or poor soil conditions (Mlingwa et al. 2000). These forests have a low number of species and seem to be subordinates (in terms of species diversity) to the other Tanzanian and Kenyan forests (i.e., poor subsets of these forests). All the affinities among the depauperated bird faunas signal a possible future dire scenario if the diversity and heterogeneity of the coastal forests is lost by further fragmentation and degradation (Lowe and Clarke 2000). Thus, the bird faunas of the degraded or scrubby forests within the main forest block (e.g. Waa) resembled those of the dry forests and woodlands near the northern border of the forest chain, which are marginal in terms of biodiversity and affinity to the coastal forest.

The PAD analysis of mammals resulted in two MPTs $(\mathrm{L}=259, \mathrm{CI}=0.33, \mathrm{RI}=0.52)$. The strict and Adams consensus of these trees had the same topology shown in Fig. 3A. The hierarchical grouping of forest fragments does not seem to follow a strict geographical gradient. The first clade (A) is formed by two groups of forests located at opposite ends of the coastal forest belt, i.e. forests found in the southern Somalia-northern Kenya region (Jubba to Arabuko-Sokoke) and forests found in southern Tanzania (Litipo to Chitoa). The forests in this clade belong to the 'Lindi' centre of endemism and other 'minor' centres of endemism (e.g., Tana-River). The sister-group to this clade (B) is a group of forests in northern Tanzania, which roughly corresponds to the 'Usambara-Kwale' and the 'Pugu Hills' centres of endemism, but which, as in birds, also includes other forests in-between (e.g., Zaraninge-Kiono). Therefore, the geographical pattern is opposite to that found in birds, although the composition of the individual clades is similar.

Basal to these clades, the cladogram shows several geographically dispersed forests (Tong'omba to Pemba). Most of the forests are degraded (e.g., Vikindu), and isolated by their island (Mafia, Pemba) or geographical location (e.g., Kimboza). Unlike in birds, the grouping of these forests is not only based on their poor species diversity but also on the presence of idiosyncratic species, which have restricted or disjunct distributions within the coastal forest range. For example, Kiwengoma, a relatively species-rich forest, is basal to species-poor forests, such as Kisiju (see Fig. 3A), and six of its species have idiosyncratic distribution, e.g., the forest generalist Chlorocebus aethiops. Like in PAD, the groupings in the cluster analysis showed also a lack of geographical correspondence (Fig. 3B). Moreover, the Mantel test (Table 3) indicated that composition similarity was not spatially autocorrelated in mammals, i.e., geographically close forests do not necessarily share similar faunas. Moreover, all high-level clusters in mammals are joined by relatively low similarity values ( $\mathrm{SS}=0.4-0.6$, Fig. $3 \mathrm{~B}$ ), suggesting low similarity among their mammal 
A.

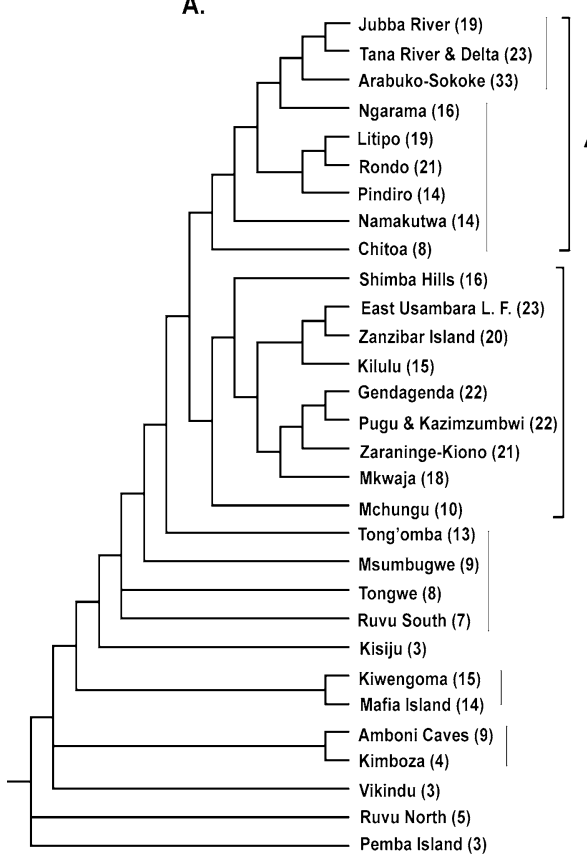

B.

A

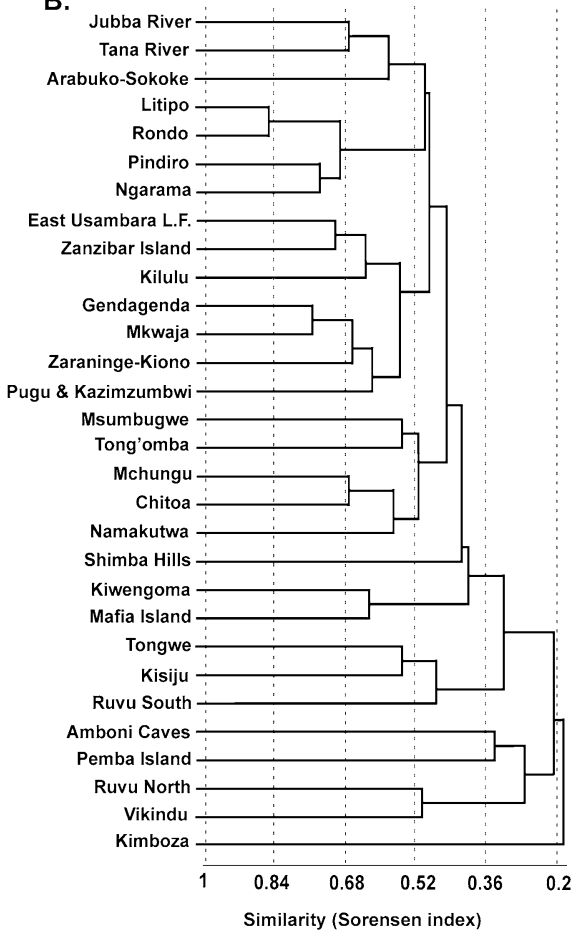

Fig. 3 Biogeographic affinities among 30 East African coastal forests based on the distributions of specialist and generalist mammals. (A) Strict consensus of two MPTs $(\mathrm{L}=259, \mathrm{CI}=0.33, \mathrm{RI}=0.52)$ from a parsimony analysis of species distributions; number of species in each forest fragment is given between brackets. (B) UPGMA tree from a cluster analysis based on Sorensen's similarity index

faunas. Thus, geographical distance is a less important factor in mammals than in birds, probably because inter-fragment dispersal in mammals is rare over distances of this magnitude (see also the lack of correlation between species richness and isolation in Table 2).

Both the PAD and cluster analyses of reptile species indicated the uniqueness of the reptile fauna in various forest fragments. The PAD analysis resulted in 93 MPTs $(\mathrm{L}=62$, $\mathrm{CI}=0.59$, RI $=0.50$ ), whose strict consensus was mostly unresolved (Fig. 4A). The Adams consensus showed only a few two-area clusters, of which only three were geographically defined (Kiwengoma/Tong' omba, Tana/Arabuko-Sokoke and East Usambara/ Gendagenda) (Fig. 4A).

This lack of resolution is probably due to the low reptile diversity in each of the forests (Mean $\pm \mathrm{SD}, 3.52 \pm 2.68$, Table 1; see also Fig. 4A), but also by the fact that at least $50 \%$ of reptile species were single-site endemics, a condition common for endemic species in the East African coastal forest (Burgess et al. 1998). The high prevalence of endemism also indicates that inter-forest movement is low in reptiles. This pattern is also reflected in the cluster analysis (Fig. 4B), where the similarity values among clusters ( $\mathrm{SS}=0.2$ ) were on average lower than in mammals, and much lower than in birds. Thus, there is very little in common between the endemic specialists reptile fauna of the different forest fragments. Moreover, the Mantel test showed that there is no correlation between reptilian compositional similarity and geographic distance among forest fragments (Table 3). Thus, the 
A.

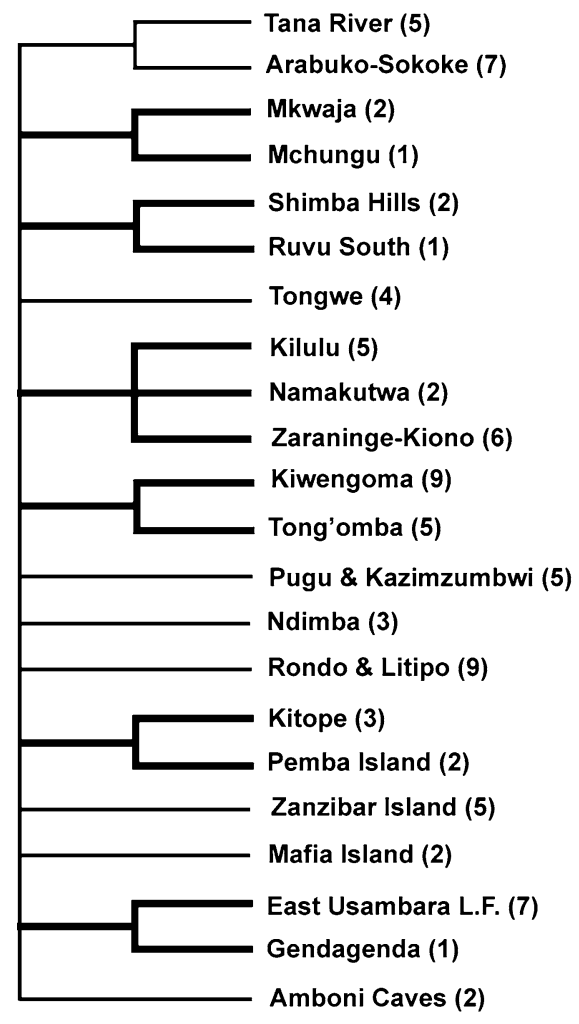

B.

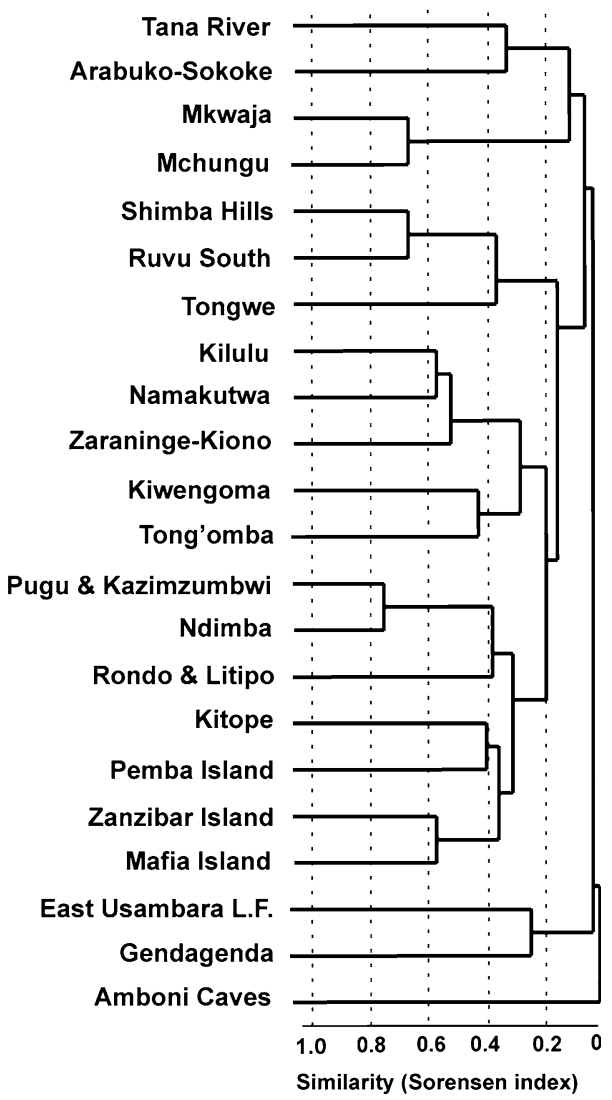

Fig. 4 Biogeographic affinities among 22 East African coastal forests based on the distributions of coastal and forest endemic specialist reptiles. (A) Strict and Adams consensus of 93 MPTs $(L=62, C I=0.59$, $\mathrm{RI}=0.50)$ from a parsimony analysis of species distributions; groups further resolved in the Adams consensus are given in bold lines. Number of species in each forest fragment is given between brackets. (B) UPGMA tree from a cluster analysis based on Sorensen's similarity index

few endemic species of reptiles with a wide distribution often exhibit a disjunct distribution (Burgess et al. 1998). Such disjunct distributions could be better explained by historical fragmentation dynamics and extinctions of once wider distributions than by contemporary ecological processes such as dispersal.

The PAD analysis for the combined data set (birds + mammals + reptiles) resulted in 35 MPTs $(\mathrm{L}=710, \mathrm{CI}=0.33, \mathrm{RI}=0.47)$. The strict consensus was mostly unresolved. The Adams consensus (Fig. 5) shows similar patterns to those found in mammals and birds. The most distal clades (A-C) are formed by forests in Kenya and northern Tanzania, which roughly correspond to the 'Usambara-Kwale' centre of endemism. Sister-group to these clades, clade (D) includes forests in the south Tanzanian 'Lindi' region, as well as Kiwengoma-Tong'omba, which form the 'Matumbi and Kichi Hills' minor centre of endemism (Burgess 2000). Clade (E) also corresponds to the 'Lindi' region. Finally, the basal clade $(\mathrm{F})$ includes forests that are geographically scattered. 


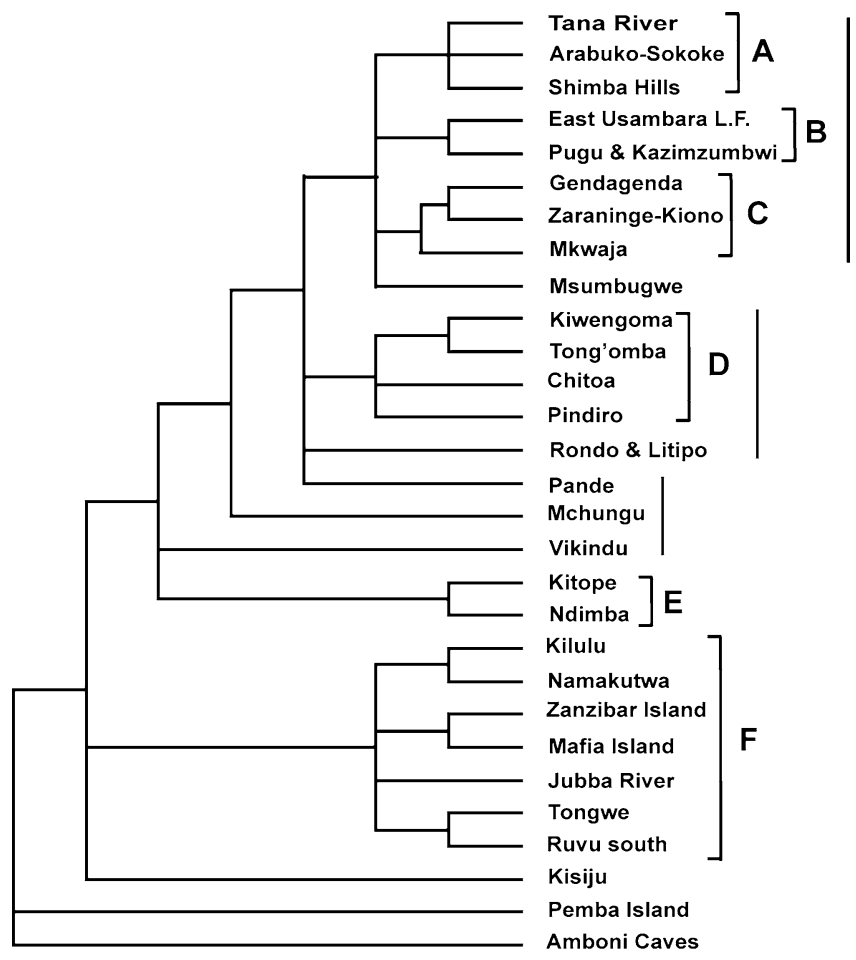

Fig. 5 Biogeographic affinities among 29 East African coastal forests based on the combined distributions of birds, mammals, and reptiles. The tree is the Adams consensus of 35 MPTs $(\mathrm{L}=710, \mathrm{CI}=0.33$, $\mathrm{RI}=0.47$ ) obtained from a parsimony analysis of species distributions

\section{Conclusions}

The East African coastal forests have been described as a diverse and heterogeneous forest ecosystem. Both current and historic factors have had a profound effect on the distribution of species (Kingdon and Howell 1993; Hawthorne 1993; Burgess et al. 1998; Lowe and Clarke 2000; Rodgers 2000; de Klerk et al. 2002a, b; Jetz et al. 2004). Like other patchy and fragmented forest systems, current forest attributes, such as size, isolation, median altitude, and elevation range (i.e., habitat diversity), had influenced the species distribution of vertebrates in the coastal forests. However, the relative importance of these ecological factors seem to vary depending on life history characteristics of the taxa studied, such as dispersal ability (birds vs. reptiles) and, within taxa, on the degree of dependence on forest resources (specialists vs. generalists). As expected for vagile species, birds seem to be able to cope with changing ecological conditions, e.g., area, forest type, and diversity, and thus their distribution appear to be driven by extinction and colonization dynamics. Moreover, both bird and mammal forest specialists showed a stronger correlation to variables related to habitat diversity such as altitude range, suggesting that habitat diversity affects species richness of groups with habitat specializations (Ricklefs and Lovette 1999). However, this conclusion requires further investigation using a direct quantification of the number (i.e., quantity) of each habitat type across the forests, as well as empirical data on the specific habitat used by each of the species. Forest generalist mammals and birds showed only a 
more general species-area relationship. The less vagile endemic reptiles seem to be less correlated to forest area and isolation measure. However, the species richness of the relict coastal endemic reptiles was correlated to altitude range, whereas forest endemic reptiles appear to concentrate in forests with relatively higher altitude. We may conclude that topographical heterogeneity and the relatively moist forests on high altitude may have provided a refugee opportunity (a suitable and stable environment) for coastal and forest endemic reptiles, respectively, both historically and contemporarily during climatic cycles. Thus, the patterns of species richness suggest that past extinctions and dispersal limitations are important factors for the distribution of forest specialist reptiles in the coastal forests. Their (most likely) relict distribution indicates that reptiles could be good candidates for tracing past environmental history, in which case, phylogeny-based (cladistic) biogeography should be the method of choice.

Our study also confirms some of the local centres of endemism identified in previous studies (Burgess 2000; Mlingwa et al. 2000). Regions such as the 'Usambara-Kwale' and the 'Lindi' centre of endemism appear as clusters of areas in mammals and birds, confirming the 'naturalness' of these regions. Moreover, our study shows that other forests should also be included within these two centres of endemism (e.g., Ngarama and Pindiro in the 'Lindi' centre of endemism).

The results from this study also indicate that PAD can be used as an alternative (complementary) method to cluster analysis for finding biogeographic affinities among areas. Unlike cluster analysis, the grouping of areas in PAD is not based on overall similarity but on maximizing congruence between geographic distributions, i.e., the correlation between taxa and areas. The MPT is the simplest explanation to the species distributions given the data: the tree that minimizes the number of changes in the biotic composition of an area required to explain its present biota. Even though species are not subjected to the same constraints as organism traits (i.e., characters are inherited from ancestor to descendant, whereas species can move freely to new areas by dispersal), an explanation that minimizes the number of biotic changes (e.g., colonization/extinction events) is still realistic if communities tend to be maintained. Our results suggest that in fact dispersal can be a strong element in keeping species as part of the community, for example, through the 'rescue effect' (Brown and Kodric-Brown 1977; McDowall 2004). The patterns found by PAD in mammals and reptiles could indicate the existence of a historical component (e.g., habitat continuity over time, fragmentation) that is less influenced by current ecological settings. PAD patterns can reflect both ecological and historical components but how far a given pattern is ecological or historical is unclear, since no phylogenetic information is included in the analysis. On the other hand, cluster methods are more sensitive to methodological artefact, i.e., sample size and index used (Rosen 1988). Moreover, the result from PAD does, in many ways, resemble an analysis of nestedness (Patterson and Atmar 1986; Azeria 2004) with the improvement that it can detect more than one nested subset.

Finally, the variation in biogeographical patterns across taxonomic and habitat specialization elucidates the need for a variety of conservation strategies to protect the vertebrate fauna of the East African coastal forests. Given the high degree of geographical correspondence (and inter-fragment dispersal) found in birds, to design large reserves with good geographical connectivity could be a good strategy for this group. In contrast, the lower affinity and weak geographical correspondence found in forest specialist mammals, and in the rare and widely dispersed (disjunct) endemic reptiles, in particular, indicate that they are less likely to maintain connectivity among forest patches. This fact makes these groups highly vulnerable to disturbances that severe the available resources (e.g. habitat diversity, structure, or stable environment) provided within each of the functionally 
isolated forest fragments. Thus, these taxa, and the specialist birds, and are likely to persist only when the remnant forests remain intact, in which case a direct 'site-based' protection would be probably the most effective conservation strategy.

Acknowledgements Ermias T. Azeria would like to thank Sida/Sarec for financial support under the auspices of Asmara program, ISP, Uppsala University. Isabel Sanmartín was supported by a European Community Marie Curie Fellowship (MCFI-2000-00794) and by the Swedish Natural Research Council (621-2003-3855). We thank Philip Clarke for his valuable comments on the manuscript, and the authors of the original survey studies for providing us with access to their data. We are especially grateful to Yonas I. Tekle for his assistance in the analysis, and to Christer G. Wiklund and an anonymous referee for their constructive criticisms on the manuscript.

\section{Appendix}

Table 4 Comparison between the centres of endemism defined by Burgess et al. (1998) and Burgess (2000) and the groupings of forests (clades A-G, see Figs. 2, 3) obtained from a parsimony analysis of birds and mammals distributions (PAD)

\begin{tabular}{lllll}
\hline Code & Forest & Endemism centre & Birds & Mammals \\
\hline JU & Jubba & & E & A \\
BO & Boni & & E & - \\
TR & Tana & TMC & A & A \\
DK & Dakatcha & & E & - \\
GD & Gede & AMC & A & - \\
AS & Arabuko-Sokoke & UK & A & A \\
MT & Mtswakara & UK & F & - \\
GA & Gandini & UK & E & - \\
TL & Teleza & UK & F & - \\
WA & Waa & UK & S (A-E) & - \\
SH & Shimba Hills & UK & A & B \\
MU & Muhaka & UK & B & - \\
DJ & Diani & UK & B & - \\
KN & Kinondo & UK & S (A-E) & - \\
DZ & Dzombo & UK & B & - \\
GN & Gongoni & UK & B & - \\
BU & Buda & UK & B & - \\
TM & Timbwa & UK & S (A-E) & - \\
MR & Mrima & UK & A & - \\
MA & Marenji & UK & B & - \\
EU & East Usambaras lowland & UK & C & B \\
KL & Kilulu & UK & F & B \\
AC & Amboni Caves & UK & - & C \\
TW & Tongwe & UK & - & S (A-B) \\
GG & Gendagenda & UK & S (C-D) & B \\
MB & Msubugwe & & S (C-D) & NS \\
MJ & Mkwaja & & - & B \\
ZK & Zaraninge-Kiono & & S (C-D) & B \\
RN & Ruvu North & - & S (A-D) & C \\
PA & Pande & S (C-D) & B \\
PU & Pugu & PM & S A-D) & C \\
KZ & Kazimzumbwi & & & S (A-B) \\
VI & Vikindu & & & \\
RS & Ruvu South & & & \\
\hline
\end{tabular}


Table 4 continued

\begin{tabular}{lllll}
\hline Code & Forest & Endemism centre & Birds & Mammals \\
\hline KM & Kimboza & & - & - \\
KI & Kisiju & & $-?$ & S (A-B) \\
MC & Mchungu & & S (A-D) & B \\
NM & Namakutwa & MKH & - & A \\
KW & Kiwengoma & MKH & D & S (A-B) \\
TO & Tong'omba & & - & S (A-B) \\
KP & Kitope & & D & A \\
NG & Ngarama & & D & A \\
PD & Pindiro & & D & A \\
ND & Ndimba & Lindi & D & A \\
CH & Chitoa & Lindi & D & A \\
LI & Litipo & Lindi & D & - \\
RO & Rondo & & D & S (A-B) \\
NY & Nyangamara & TZO & - & B \\
PI & Pemba island & TZO & S (A-E) \\
ZI & Zanzibar Island & TZO & S (A-E) & S (A) $)$ \\
MI & Mafia Island & S(A-E) & \\
\hline
\end{tabular}

$\mathrm{TMC}=$ Tana Minor center; $\mathrm{AMC}=$ Arabuko Minor centre UK = Usambara-Kwale; PM = Pugu minor; $\mathrm{MKH}=$ Matumbi and Kichi hills; LN = Lindi; TZO = Tanzania offshore $(-)=$ Data on species distributions not available. $\mathrm{S}$ = Forest biota which do not form a clade by themselves, but form basally diverge to clades shown bracket 


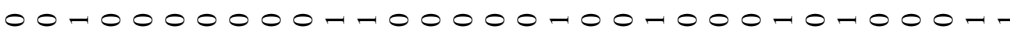
$0-1000-10-1-100000-0-000000-000-1$ $0-10000-0-10-0000-010000000000-0$ $00-1-0-00000-000000-000-00-0-00-1$ $-0-7-0-0-0-100-10-0-100-10-0-0-1$

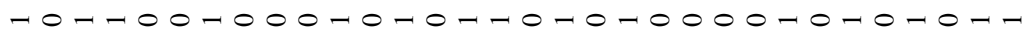
$0-000000000000-0000-000000-0-00-1$ - $0-0-0-000-1-0-10-00000-10-0-1-1-1$ $00-0-0-000-1-0-1-10-000-1-1-0-1-1$ $00-0-00000-0-0-1000-000000-0-0-1$ O-1- - - $00000-0-0-00-0-0000-1-0-10-1$ $-0-0-0-000-0-0-1000-0000-0-0-1-1$ $00-0-0-000-1-0-00-0-000-10-0-0-1-1$ $00-000-0000000-00-0000000000-0-1$

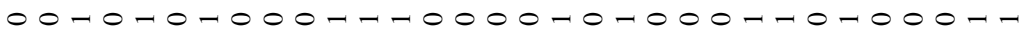

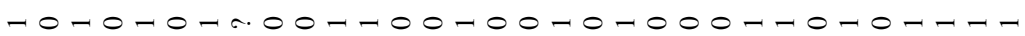
-1- $-0-0-0-000-000-00-0-000-00-0-0-1$

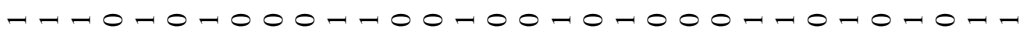

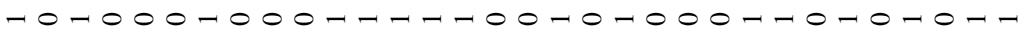

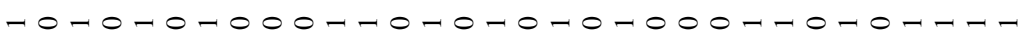
-

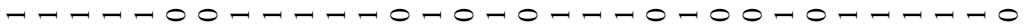
o-1 - $-0-000-1-1000-0-0000-0-1-1-1$ $00-0-0-000-0-1000-0-1000-0-1-1-1$ $00-1-0-00-1-0-0-0-0-0000-0-1-10-1$ $-0-0-0-000-00-000-0-0000000-10-1$ - O$-1-0-00000-10-000-0-000000-1000-1$

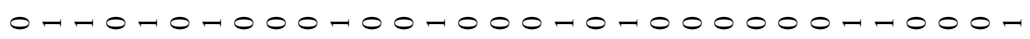
$0-1000-000-00-000-0-100-000-000-1$ - - - - - - $00000-00-000-0-1000-0-10-10$ -ー - $0-00000000-10-000-000000000000-1$

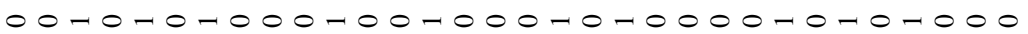
- $0-000-000-0-100000-100-0-10-0-0$ - $0-0-0-00000-1000-00-000-0-1-10-0$ -1- - - - - $0000000-10-000-0-100-1-7-10-1$ $-0-0000000-1-1000-0-100-00-00000$ - $0-1-1-000-10-001-0-10-10-1-10-1$ $00-000-000-10-1000-00-100-100-100000$ -

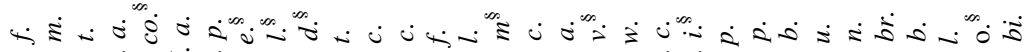

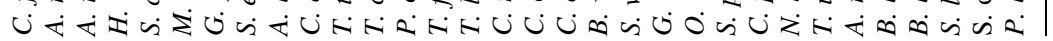




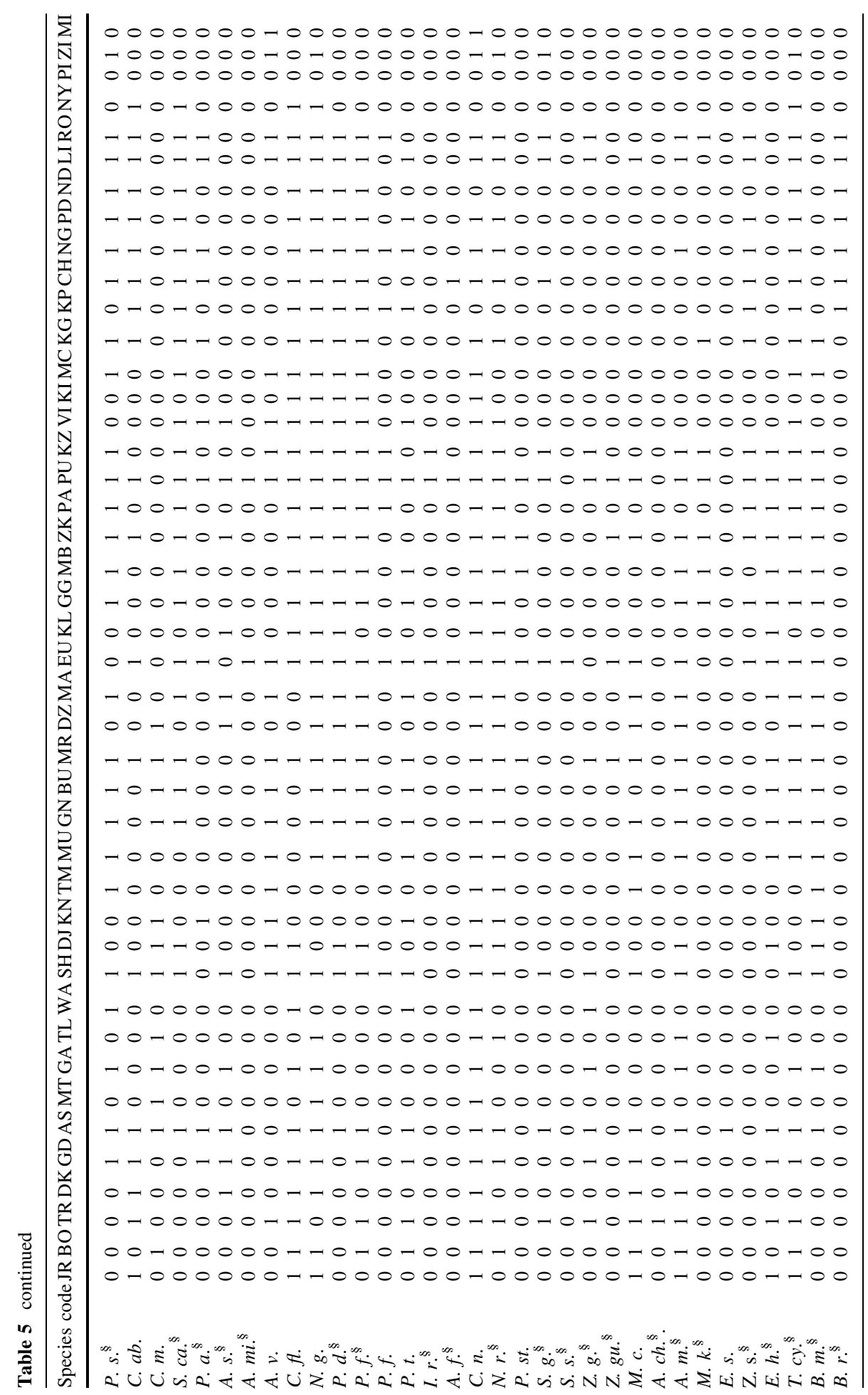




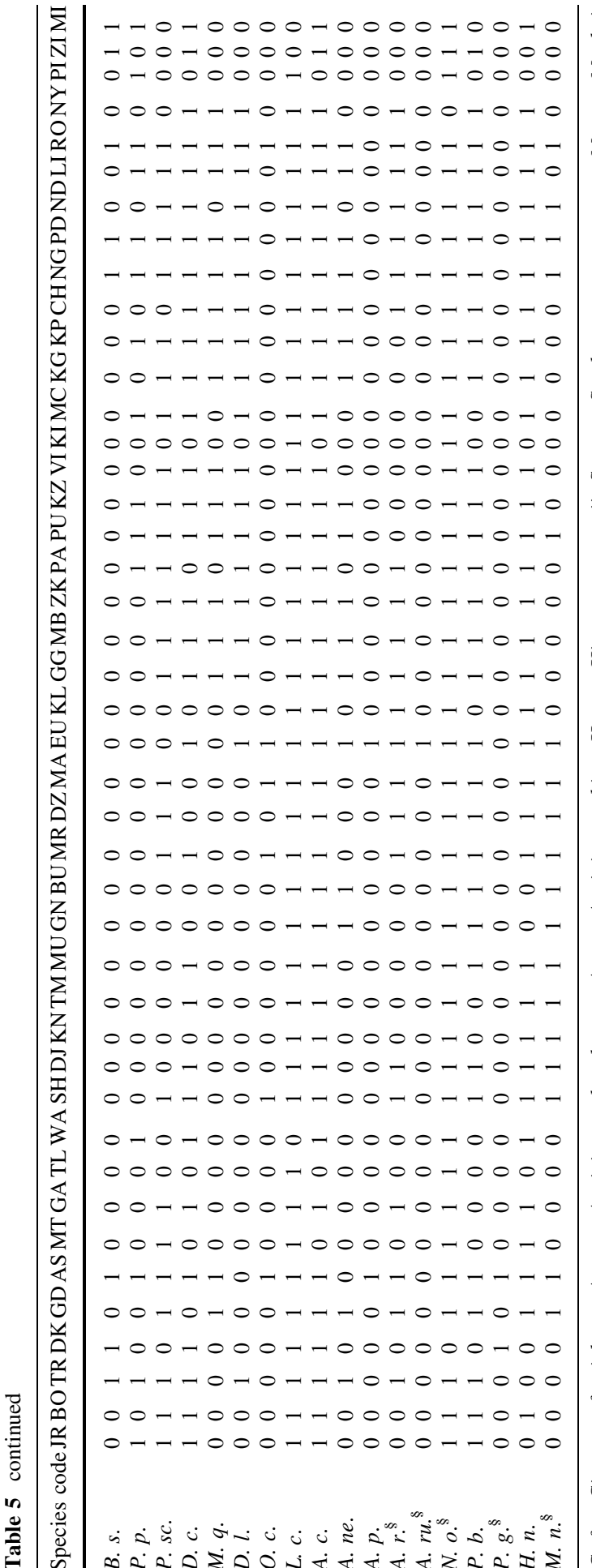

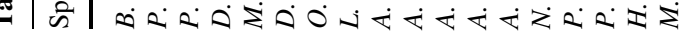

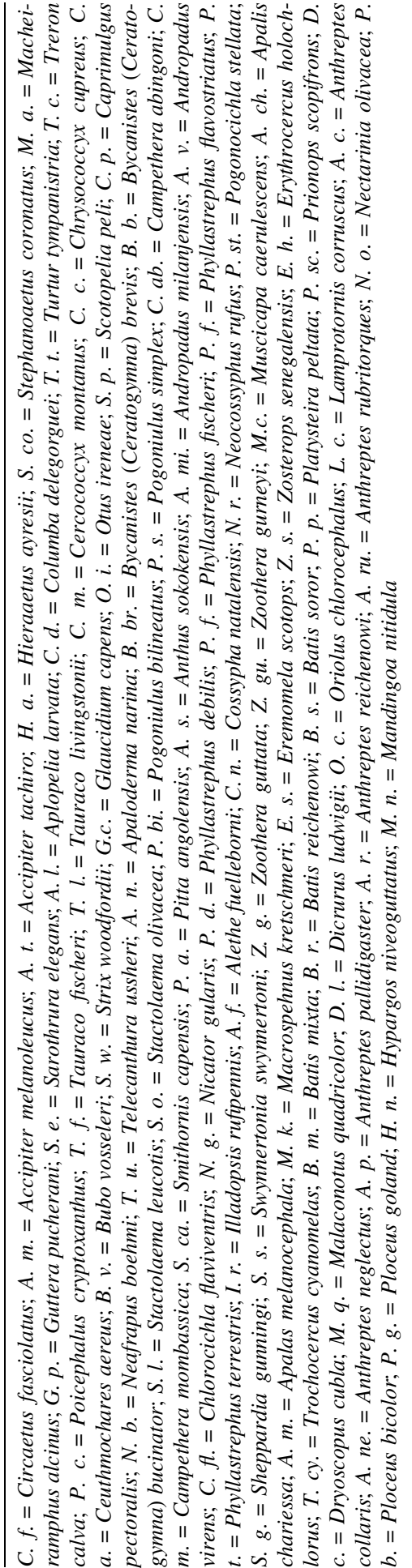


$00-000000000-00-10000000000000-00$ $-0-0000000-00-0-000-000000-1-1-00$ $0000000000000-00-0000000000000000$ $00-000000000000-0-000000000000000$ $0000000000-00-0-10-00-00-0-0-0000$ $000000000-100-0-00000-1000-100000$ $0000000000-0000-0000000000-00-000$ $000000000-10-10-10000-0000-00-000$ $000000000-10-10-10000-0000-000000$ $0000000000-00-0-0000000000-000000$ $00000000-0-00-0-00-0000000-00000-$ $00-000000000000-10-0000000-000-00$ $0000000000-0000-0-00000000-000000$ $0000000000000-0-00000000000000000$ $000000000000000-10-00000000000000$ $0000000000-0000-00-00000000000000$ $-000000-0-10-10-10-0000000-0-100-$ $0000000000-00000-0-00000000000000$ $-00000-000000-0-0-1-0000000-000-00$ $0000000000-00-0-1-1-0000000-000000$ $0000000000-0-1000000000000-0-0000$ $00000-0000-00-0-1-10000000-0-100-$ $0000-00000-00-0-0-000000000000000$ $0-0000000000-00-1-1000000000-00000$ $0000000000-00-0-1-000000000-000-0$ $-000000000-00-0-1-100000000-10-00-$ $00000000000-000-1-1000000000-00000$ $-00-000000-1-10-10-0000-0-1-1-1-0$ $0000000000-000-1-0-0-1-00-100-0-0$ $0000000000-0-00-00-000000-10-10-0$

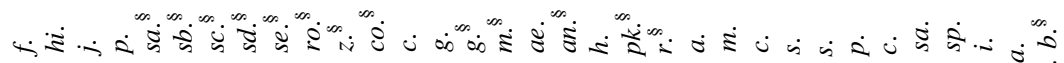

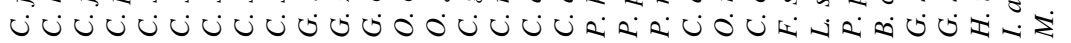




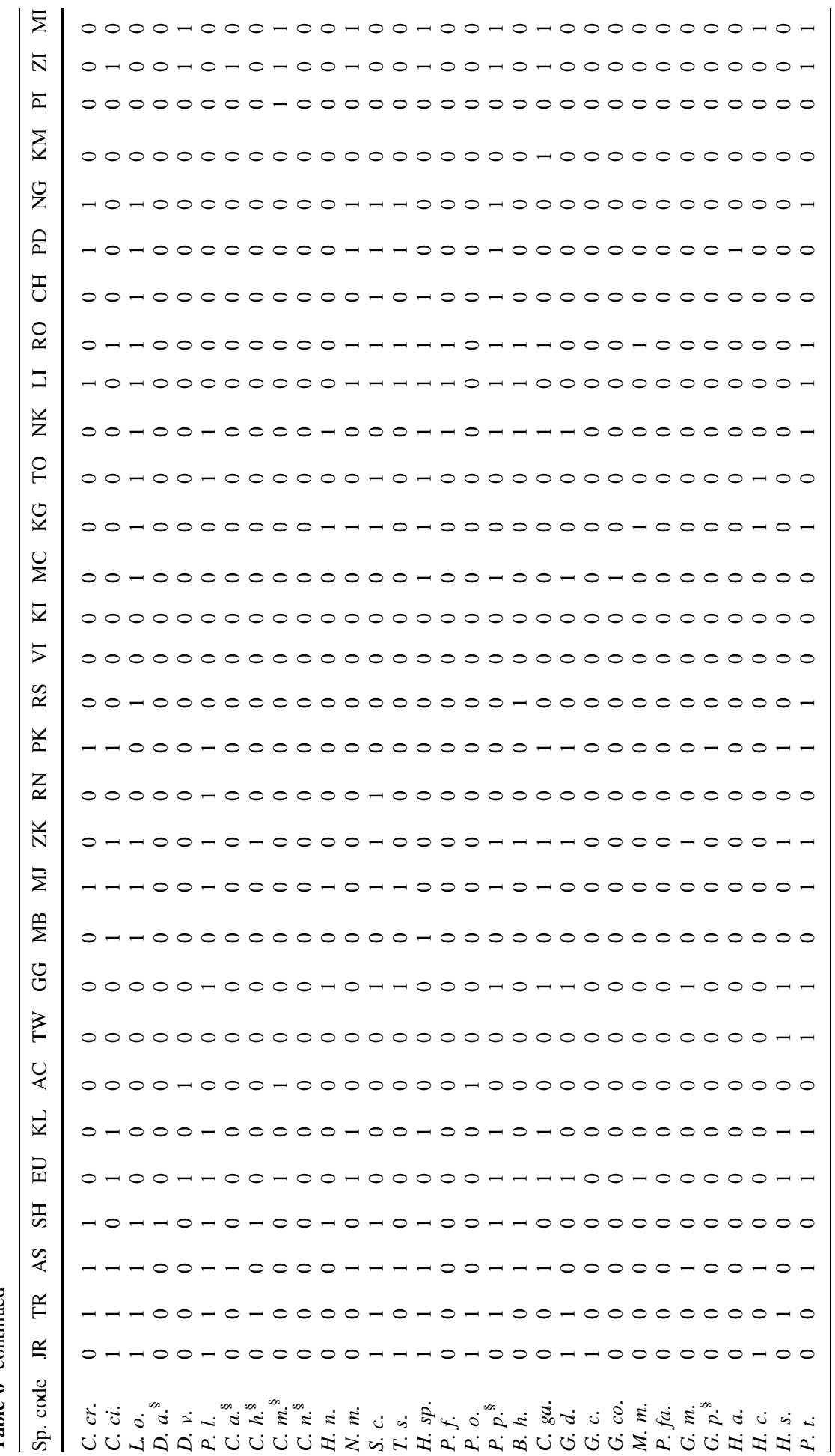




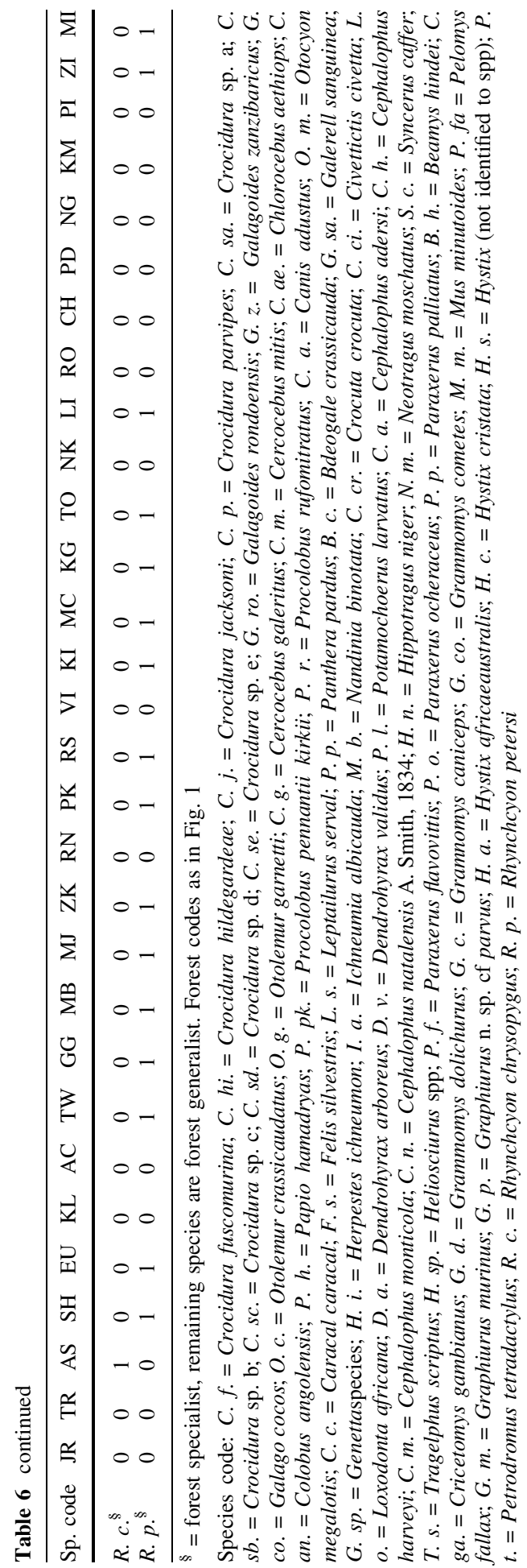




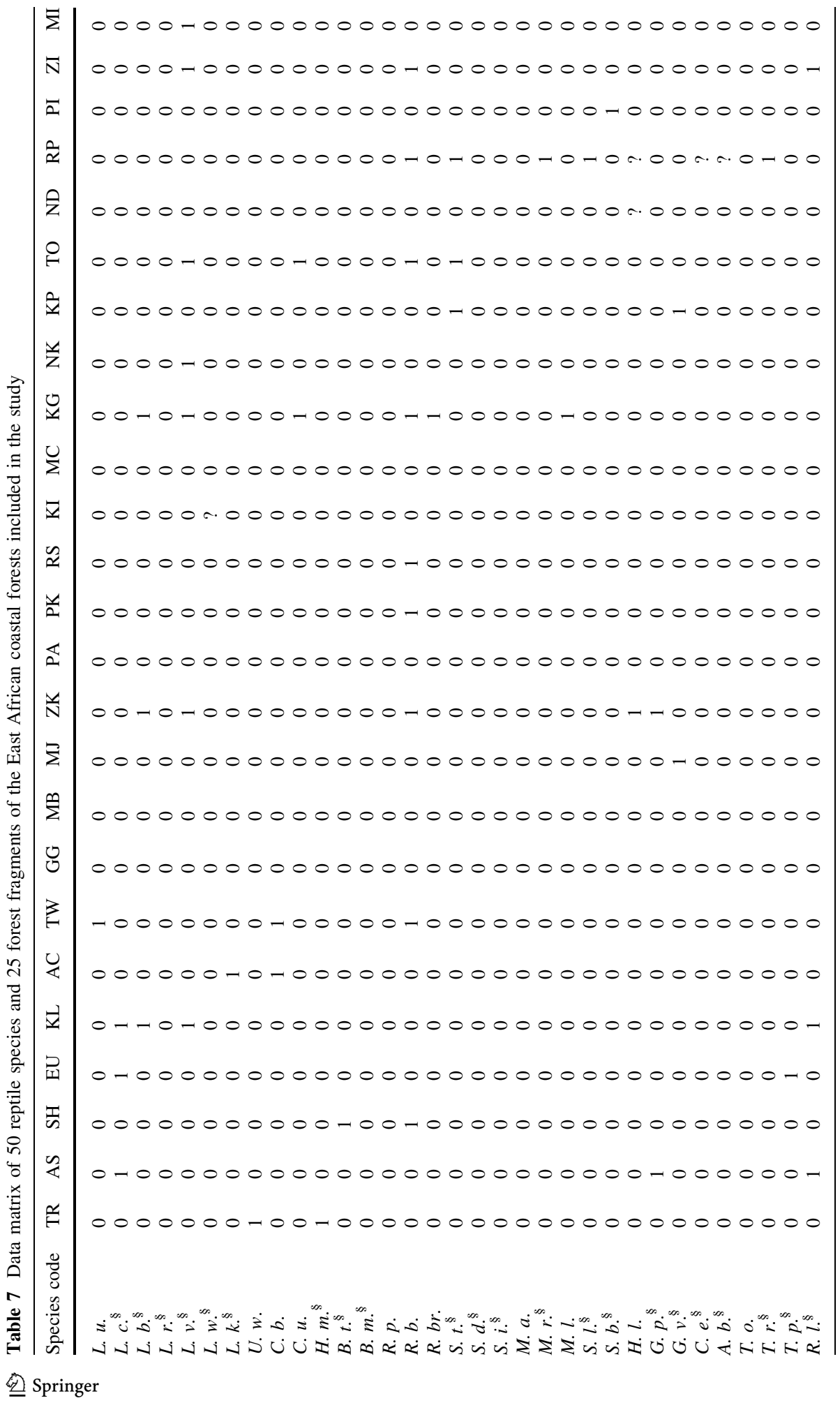




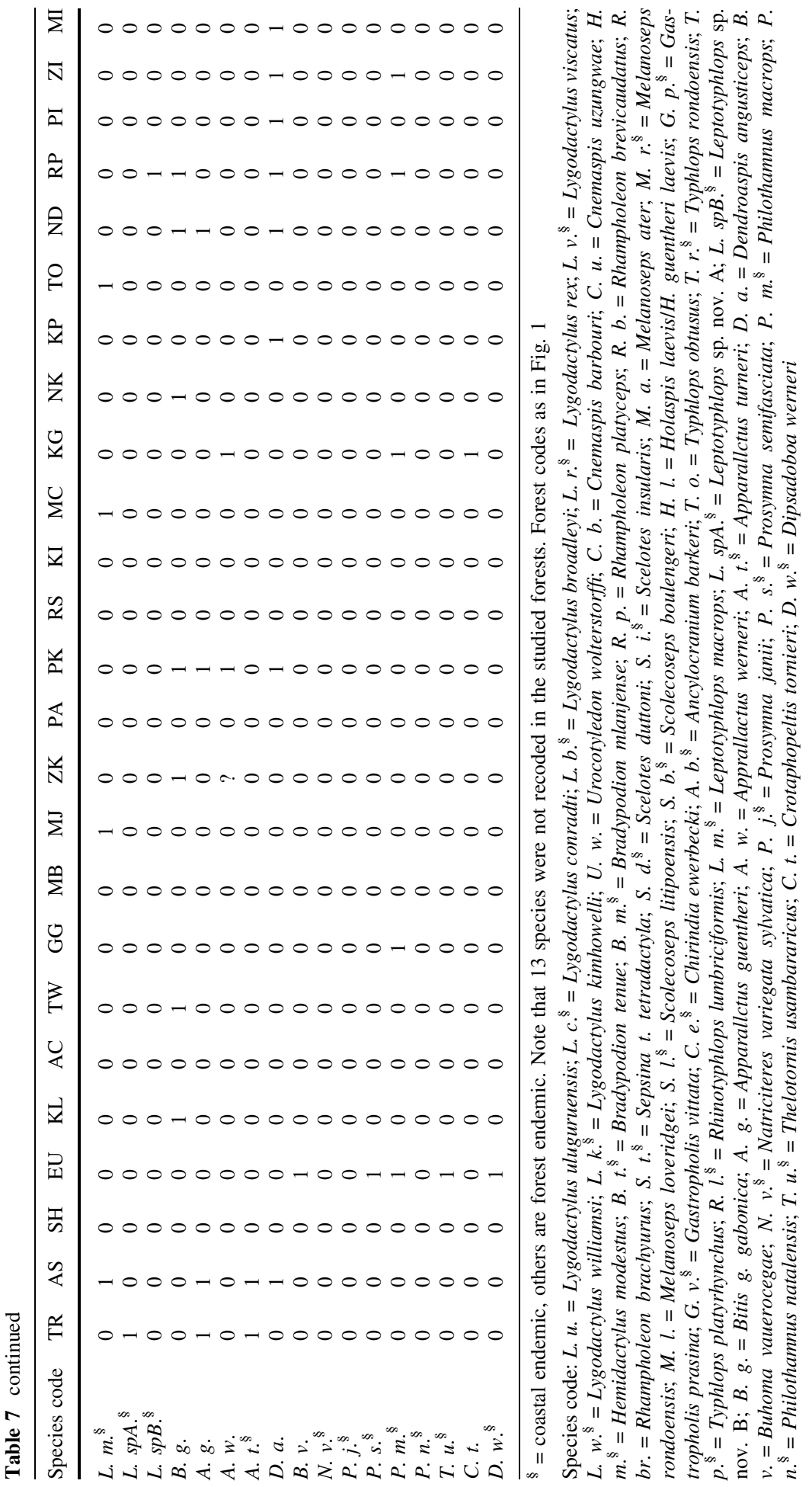




\section{References}

Andrén H (1994) Effects of habitat fragmentation on birds and mammals in landscapes with different proportions of suitable habitat: a review. Oikos 71:355-366

Anonymous (2003) Ecosystem profile: Eastern Arc mountains and coastal forests of Tanzania and Kenya biodiversity hotspot. Critical Ecosystem Partnership Fund (CEPF). Prepared by Conservation International (CI) and International Centre of Insect Physiology and Ecology (ICIPE), Washington, USA

Ås S, Bengtsson J, Ebenhard T (1997) Archipelagoes and theories of insularity. Ecol Bull 46:88-116

Azeria ET (2004) Terrestrial bird community patterns on the coralline islands of the Dahlak Archipelago. Global Ecol Biogeogr 13:177-187

Broadley DG, Howell KM (2000) Reptiles. In: Burgess ND, Clarke GP (eds) The coastal forests of Eastern Africa. IUCN, Gland, Switzerland and Cambridge, UK, pp 191-200

Brooks T, Balmford A, Burgess N, Fjeldså J, Hansen LA, Moore J, Rahbek C, Williams P (2001) Toward a blueprint for conservation in Africa. BioScience 51:613-624

Brooks TM, Mittermeier RA, Mittermeier CG, daFonseca GAB, Rylands AB, Konstant WR, Flick P, Pilgrim J, Oldfield S, Magin G, Hilton-Taylor C (2002) Habitat loss and extinction in the hotspots of biodiversity. Conserv Biol 16:909-923

Brooks DR, Van Veller MGP (2003) Critique of parsimony analysis of endemicity as a method of historical biogeography. J Biogeogr 30:819-825

Brown J, Kodric-Brown A (1977) Turnover rates in insular biogeography: effect of immigration on extinction. Ecology 58:445-449

Burgess ND (2000) Global importance and patterns in the distribution of coastal forest species. In: Burgess ND, Clarke GP (eds) The coastal forests of eastern Africa. IUCN, Switzerland and Cambridge, UK, pp 235-248

Burgess ND, Clarke GP (eds) (2000) The coastal forests of Eastern Africa. IUCN, Gland, Switzerland and Cambridge, UK

Burgess ND, Kock D, Cockle A, FitzGibbon CM, Jenkins P, Honess P (2000) Mammals. In: Burgess ND, Clarke GP (eds) The coastal forests of Eastern Africa. IUCN, Gland, Switzerland and Cambridge, UK, pp 173-190

Burgess ND, Clarke GP, Rodgers WA (1998) Coastal forests of Eastern Africa: status, endemism patterns and their potential causes. Biol J Linn Soc 64:337-367

Burgess N, D'Amico Hales J, Underwood E, Dinerstein E, Olson D, Itoua I, Schipper J, Ricketts T, Newman K (2004) Terrestrial ecoregions of Africa and Madagascar a continental assessment. Island Press, Washington DC, pp 550

Cavieres LH, Arroyo MTK, Posadas P, Marticorena C, Matthei O, Rodríguez R, Squeo FA, Arancio G (2002) Identification of priority areas for conservation in an arid zone: application of parsimony analysis of endemicity in the vascular flora of the Antofagasta region, northern Chile. Biodivers Conserv $11: 1301-1311$

Clarke GP (2000a) Defining the coastal forests. In: Burgess ND, Clarke GP (eds) The coastal forests of Eastern Africa. IUCN, Gland, Switzerland and Cambridge, UK, pp 9-26

Clarke GP (2000b) Climate and climate history. In: Burgess ND, Clarke GP (eds) The coastal forests of Eastern Africa. IUCN, Gland, Switzerland and Cambridge, UK, pp 47-68

Clarke GP, Karoma NJ (2000) History of anthropic disturbance. In: Burgess ND, Clarke GP (eds) The coastal forests of Eastern Africa. IUCN, Gland, Switzerland and Cambridge, UK, pp 251-262

Cornelius C, Cofré H, Marquet PA (2000) Effects of habitat fragmentation on bird species in a relict temperate forests in semiarid Chile. Conserv Biol 14:534-543

de Klerk HM, Crowe TM, Fjeldså J, Burgess ND (2002a) Patterns of species richness and narrow endemism of terrestrial birds species in the Afrotropical region. J Zool 256:327-342

de Klerk HM, Crowe TM, Fjeldså J, Burgess ND (2002b) Biogeographical patterns of endemic terrestrial Afrotropical birds. Divers Distrib 8:147-162

deMenocal PB (1995) Plio-pleistocene African climate. Science 270:53-59

Diamond AW (1981) The continuum of insularity: the relevance of equilibrium theory to the conservation of ecological islands. An overview of the fourth East African wildlife symposium. Afr J Ecol 19:209-212

Fjeldså J, Lovett JC (1997) Geographical patterns of young and old species in African forest biota: the significance of specific montane areas as evolutionary centres. Biodivers Conserv 6:325-346

Fjeldså J, Ehrlich D, Lambin E, Prins E (1997) Are biodiversity 'hotspots' correlated with current ecoclimatic stability? A pilot study using the NOAA-AVHRR remote sensing data. Biodivers Conserv 6:401422

Foufopoulos J, Ives AR (1999) Reptile extinctions on land-bridge islands: life-history attributes and vulnerability to extinction. Am Nat 153:1-25 
García-Barros E, Gurrea P, Luciáñez MJ, Cano JM, Munguira ML, Moreno JC, Sainz H, Sanz MJ, Simón JC (2002) Parsimony analysis of endemicity and its application to animal and plant geographical distributions in the Ibero-Balearic region (western Mediterranean). J Biogeogr 29:109-124

Gascon C, Lovejoy TE, Bierrgaard RO, Malcolm JR, Stouffer PC, Vasconcellos HL, Laurance WF, Zimmerman B, Toucher M, Borges S (1999) Matrix habitat and species richness in tropical forest remnants. Biol Conserv 91:223-229

Hanski I, Thomas CD (1994) Metapopulation dynamics and conservation: a spatially explicit model applied to butterflies. Biol Conserv 68:167-180

Hawthorne WD (1993) East African coastal forest botany. In: Lovett JC, Wasser SK (eds) Biogeography and ecology of the rain forests of Eastern Africa. Cambridge University Press, Great Britain, Cambridge, pp 57-99

Jetz W, Rahbek C (2002) Geographic range size and determinants of avian species richness. Science 297:1548-1551

Jetz W, Rahbek C, Colwell RK (2004) The coincidence of rarity and richness and the potential signature of history in centers of endemism. Ecol Lett 7:1180-1191

Kearney M (2002) Fragmentary taxa, missing data, and ambiguity: mistaken assumptions and conclusions. Syst Biol 51:369-381

Kingdon J, Howell KM (1993) Mammals in the forests of eastern Africa. In: Lovett JC, Wasser SK (eds) Biogeography and ecology of the rainforests of eastern Africa. Cambridge University Press, Cambridge, UK, pp 338-331

Krebs CJ (1999) Ecological methodology, 2nd edn. Addison-Wesley Educational Publishers, California

Lomolino MV (2000) A call for a new paradigm of island biogeography. Global Ecol Biogeogr 9:1-6

Lomolino MV, Brown JH, Davis R (1989) Island biogeography of montane forest mammals in the American Southwest. Ecology 70: 180-194

Lowe AJ, Clarke GP (2000) Vegetation structure. In: Burgess ND, Clarke GP (eds) The coastal forests of Eastern Africa. IUCN, Gland, Switzerland and Cambridge, UK, pp 103-113

MacArthur RH, Wilson EO (1967) The theory of island biogeography. Princeton University Press, Princeton

McCune B, Mefford MJ (1997) Multivariate analysis of ecological data, version 3.19, MjM Software, Gleneden Beach, Oregon, USA

McDowall RM (2004) What biogeography is: a place for process. J Biogeogr 31:345-351

Mlingwa COF, Waiyaki EM, Bennun LA, Burgess ND (2000) Birds. In: Burgess ND, Clarke GP (eds) The coastal forests of Eastern Africa. IUCN, Gland, Switzerland and Cambridge, UK, pp 149-172

Morand S (2000) Geographic distance and the role of island area and habitat diversity in the species area relationships of four Lesser Antillean faunal groups: a complementary note to Ricklefs and Lovette. J Anim Ecol 69:1117-1119

Moreau RE (1933) Pleistocene climatic changes and the distribution of life in East Africa. J Ecol 21:415435

Morrone JJ (1994) On the identification of areas of endemism. Syst Zool 43:438-441

Myers N, Mittermeier RA, Mittermeier CG, da Fonseca GAB, Kent J (2000) Biodiversity hotspots for conservation priorities. Nature 403:853-858

Nekola JC, White PS (1999) The distance decay of similarity in biogeography and ecology. J Biogeogr 26:86-878

Newmark WD (2002) Conserving biodiversity in East African forests. Springer, Berlin

Page RDM (1998) GeneTree: comparing gene and species phylogenies using reconciled trees. Bioinformatics 14:819-820

Patterson BD, Atmar W (1986) Nested subsets and the structure of insular mammalian faunas and archipelagos. Biol J Linn Soc 28:65-82

Patterson BD, Brown JH (1991) Regionally nested patterns of species composition in granivorous rodent assemblages. J Biogeogr 18:395-402

Power DM (1975) Similarity among avifaunas of the Galápagos islands. Ecology 56:616-626

Ricklefs RE, Schluter D (1993) Species diversity: regional and historical influences. In: Ricklefs RE, Schluter D (eds) Species diversity in ecological communities. Chicago University Press, Chicago, USA, pp 350-363

Ricklefs RE, Lovette IJ (1999) The roles of island area per se and habitat diversity in the species area relationships of four Lesser Antillean faunal groups. J Anim Ecol 68:1142-1160

Rodgers WA (2000) Why a book on coastal forests? In: Burgess ND, Clarke GP (eds) The coastal forests of Eastern Africa. IUCN Gland, Switzerland and Cambridge, UK, pp 3-8

Rosen BR (1988) From fossils to earth history: applied historical biogeography. In: Myers AA, Giller PS (eds) Analytical biogeography: an integrated approach to the study of animal and plant distributions. Chapman and Hall, London, pp 437-481 
Rosenzweig ML (1995) Species diversity in space and time. Cambridge University Press, New York

Stuart SN (1981) A comparison of the avifaunas of seven East African forest islands. Afr J Ecol 19:133-152

Swafford DL (2002) PAUP*: phylogenetic analysis using parsimony (*and other methods). Sinauer Associates, Sunderland, MA, USA

Trejo-Torres JC, Ackerman JD (2001) Biogeography of the Antilles based on a parsimony analysis of orchid distributions. J Biogeogr 28:775-794

Trejo-Torres JC, Ackerman JD (2002) Composition patterns of Caribbean limestone forests: are parsimony, classification, and ordination analyses congruent? Biotropica 34:502-515

Van Tongeren OFR (1995) Cluster analysis. In: Jongman RHG, TerBraak CJF, van Tongeren OFR (eds) Data analysis in community and landscape ecology. Pudoc Wageningen, Netherlands, pp 174-212

Watson DM (2002) A conceptual framework for studying species composition in fragments, islands and other patchy ecosystems. J Biogeogr 29:823-834

Welter-Schultes FW, Williams MR (1999) History, island area and habitat availability determine land snail species richness of Aegean islands. J Biogeogr 26:239-249

Whittaker RJ (1998) Island biogeography: ecology, evolution and conservation. Oxford University Press, Oxford

WWF-EARPO (2002) Eastern African coastal forest program. Younge A, Negussie G, Burgess N (Authors). Regional workshop report. Nairobi, 4-7 February 2002, Nairobi, Kenya 